Bulletin d'Histoire Contemporaine de l'Espagne

$54 \mid 2020$

Les espaces du politique dans l'Espagne du Trienio liberal (1820-1823)

\title{
Gabriel Audisio, Pierre André-May et la revue Intentions(1922-1924)
}

Gabriel Audisio, Pierre André-May y la revista Intentions (1922-1924)

Gabriel Audisio, Pierre André-May and the revue Intentions (1922-1924)

\section{Christian DE PAEPE}

\section{(2penEdition}

\section{Journals}

Édition électronique

URL : http://journals.openedition.org/bhce/2983

DOI : $10.4000 /$ bhce.2983

ISSN : 1968-3723

\section{Éditeur}

Presses Universitaires de Provence

\section{Édition imprimée}

Date de publication : 1 janvier 2020

ISSN : 0987-4135

\section{Référence électronique}

Christian DE PAEPE, « Gabriel Audisio, Pierre André-May et la revue Intentions(1922-1924) », Bulletin d'Histoire Contemporaine de l'Espagne [En ligne], 54 | 2020, mis en ligne le 01 juillet 2020, consulté le 30 décembre 2020. URL : http://journals.openedition.org/bhce/2983 ; DOI : https://doi.org/10.4000/bhce. 2983

Ce document a été généré automatiquement le 30 décembre 2020.

Bulletin d'histoire contemporaine de l'Espagne 


\title{
Gabriel Audisio, Pierre André-May et la revue Intentions(1922-1924)
}

\author{
Gabriel Audisio, Pierre André-May y la revista Intentions (1922-1924) \\ Gabriel Audisio, Pierre André-May and the revue Intentions (1922-1924)
}

\section{Christian DE PAEPE}

1 L'histoire de la revue littéraire des années vingt, Intentions (1922-1924), a été retracée, il y a vingt-cinq ans, par Béatrice Mousli ${ }^{1}$. Basée essentiellement sur une analyse détaillée du contenu de la publication, replacée dans un contexte littéraire et artistique français plus large, l'étude s'appuie également sur des témoignages oraux de son fondateur et directeur, Pierre André-May (1901-1999), et sur un nombre important de pièces inédites de sa correspondance avec une dizaine d'intellectuels et écrivains français² ${ }^{2}$.

2 L'analyse montre que les littératures étrangères ne sont que faiblement représentées dans Intentions, sauf les lettres hispaniques qui constituent une notable exception grâce surtout à l'impulsion de Valery Larbaud. Le numéro double 23-24 (avril-mai 1924) est même exclusivement dédié à " la jeune littérature espagnole ». Pierre André-May a soigneusement conservé la documentation originale relative à ce numéro spécial : correspondance, textes espagnols originaux autographes et notices biobibliographiques, traductions françaises manuscrites et autres matériaux. Vers la fin de sa vie et après sa mort, ses archives ont été dispersées. Lors de recherches antérieures ${ }^{3}$, le hasard m'a mis sur la piste d'une partie du fonds hispanique de cet important ensemble de documents littéraires qui, selon toute vraisemblance et pour des raisons que j'ignore, n'a pas pu être consulté par la première biographe de la revue. Le dossier conservé concerne aussi bien l'histoire de la réception et diffusion de la

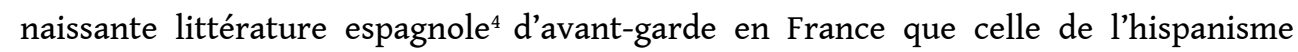
français ${ }^{5}$.

3 En la présente occasion, je veux m'attacher avant tout aux documents inédits qui illustrent la relation culturelle et littéraire et l'amitié entre le directeur et éditeur parisien Pierre André-May et un jeune collaborateur de sa revue, le poète et critique Gabriel Audisio (1900-1978). La présence assez accusée de cet écrivain français parmi un 
lot de papiers littéraires axés surtout sur le monde hispanique, s'explique sans doute par sa participation active, comme traducteur, au numéro spécial sur la jeune littérature espagnole. Au-delà de cet aspect particulier, l'analyse de la correspondance permet de se faire une idée assez précise des premières années de production littéraire de l'écrivain, résidant à l'époque en Algérie et plus tard membre de l'Ecole appelée d'Alger. Sa correspondance avec André-May couvre exactement les trois années d'existence de la revue Intentions. Il eût été fort intéressant de pouvoir compléter la documentation épistolaire unidirectionnelle par sa contrepartie ${ }^{6}$. Malgré l'absence de la deuxième voix de ce dialogue littéraire et artistique, le point de vue critique d'un jeune intellectuel français vivant dans la périphérie, l'Afrique française coloniale, jette une lumière originale et complémentaire sur l'histoire d'une revue littéraire avant tout parisienne.

\section{De «Cher monsieur» à «Mon cher ami»: trois ans d'une amitié culturelle (1922-1925)}

4 Au début de l'année 1922, Gabriel Audisio, né à Marseille (1900), fils d'une famille d'immigrés d'origine italienne ${ }^{7}$, réside à Alger comme fonctionnaire au Gouvernement Général. Il vient de commencer modestement une carrière de poète et critique littéraire. Il a à peine vingt-deux ans. Pierre André-May, fils unique d'un médecin directeur du Journal de médecine interne ${ }^{8}$, vit à Paris. Beaucoup plus intéressé par la vie littéraire que par ses études de droit, il vient de lancer une nouvelle revue littéraire, Intentions. Il a vingt-et-un ans. Pendant presque trois ans, plus précisément de février 1922 à janvier 1925, ces deux jeunes intellectuels français de formation classique et appartenant à la mouvance artistique novatrice, vont nouer une relation littéraire et culturelle autour de cette revue: l'un comme directeur, éditeur, rédacteur, avec des 'airs de grand frère', cherchant à donner dans la capitale française une 'place bien à elle' à sa 'petite revue' parmi la pléiade de nouvelles revues culturelles et littéraires du début des années vingt ${ }^{9}$; l'autre comme collaborateur, d'abord sur invitation, puis rapidement de manière spontanée, et comme poète et critique, cherchant à participer activement, depuis la périphérie de l'Afrique coloniale française, à la vie artistique d'un des grands centres de la culture européenne en pleine transformation.

5 La documentation conservée permet de conclure que les deux amis correspondants ne se sont probablement rencontrés physiquement qu'une (ou tout au plus deux) fois pendant toute cette période de trois ans et que le support matériel de leur amitié a été presque exclusivement épistolaire. Après deux mois de contact par lettres, Audisio entreprend un voyage à Paris au printemps de 1922. Une fois arrivé dans la capitale française il écrit à André-May (carte pneumatique du 5 avril) : «Du fond des Afriques j'arrive. [...] J'attends de faire votre connaissance...». Dans la lettre suivante (10 avril), il propose une deuxième visite. Le ton passe tout de suite d'officiel à amical : le "Cher monsieur » des premières lettres est remplacé par «Mon cher ami». Toutes ses lettres commenceront et s'achèveront dorénavant par l'une ou l'autre formule amicale. Reparti de Paris quelques jours plus tard, sans avoir revu André-May, Audisio écrit depuis Marseille le 16 avril, sans doute en réponse à une lettre de May: « Je regrette aussi vivement que vous de n'avoir pas eu l'occasion de vous revoir avant mon départ de Paris. [...] J'ai cependant été très heureux de serrer votre main au passage. Je le serai encore d'avoir de temps à autre de vos nouvelles.» Une main serrée au passage, l'espoir 
d'un contact épistolaire régulier, et voilà qu'une amitié est née et nouée pour de longues années. Aucune rencontre ultérieure n'est relatée dans la petite quarantaine de lettres envoyées pendant la période de la publication d'Intentions. En août 1923 Audisio écrit: « Je rentre de France. [...] Je ne vous ai pas vu [...] - pour cause : je n'ai pas été à Paris ». Pour l'année 1924, rien non plus.

6 La distribution des trente-neuf pièces de correspondance répertoriées (26 lettres, 10 cartes postales, 2 cartons et une carte pneumatique) sur les trois ans de contact épistolaire est assez éloquente. Les six premiers mois (de février à juillet 1922) livrent à eux seuls le tiers de la totalité des missives. Ces treize pièces sous-tendent et ponctuent avec grande régularité l'amitié naissante et grandissante entre les deux intellectuels. Ensuite, une fois la base bien établie et l'amitié fermement soudée, à partir de l'automne 1922 et jusqu'à l'hiver 1924, la fréquence des contacts épistolaires tournera autour de cinq missives par semestre: cinq pour les mois de septembre à novembre 1922, six pour mars à août 1923 et quatre pour le reste de l'année, cinq entre février et juillet 1924 et quatre pour le restant de cette année. Au tout début de l'année 1925, juste après la disparition de la revue, la correspondance se limite à deux brèves missives envoyées sous une seule et même enveloppe.

De temps à autre les deux correspondants thématisent l'intensité de leurs contacts épistolaires. Tel est le cas, par exemple, en juin 1922 quand André-May dut s'excuser (dans une lettre inconnue jusqu'à présent) pour avoir trop tardé à répondre à une lettre de son collaborateur. Celui-ci lui répond: «Ne vous excusez pas. Vous devez avoir une correspondance toujours considérable à tenir au courant et il est normal que vous n'y puissiez pas satisfaire sans à-coup.» Après les grandes vacances de cette même année, Gabriel Audisio écrit (le 28 septembre): «Merci de votre carte. Il y avait assez longtemps que nous ne nous étions plus donné des nouvelles.» Au cours de l'année 1924, les contacts se font plus rares et les messages plus courts (sauf pour la lettre du 4 novembre quand Audisio discute âprement l'opinion négative d'André-May au sujet de Corydon de Gide). La carte postale du 11 janvier 1925 est teintée d'angoisse : " Je ne reçois rien de vous ni Intentions. Je pense que cela n'est dû à rien de fâcheux. [...] Écrivez-moi quelques lignes. " Cette carte postale accompagnera la lettre d'adieu d'Audisio du lendemain (12 janvier 1925) : « La carte ci-jointe que je vous écrivis hier n'a plus d'utilité. Votre lettre, reçue ce matin, me navre. Ainsi Intentions à son tour disparaît. » Et d'ajouter : « Je serai toujours heureux de rester en relation avec vous, soyez-en persuadé. Je vous serre la main très cordialement. » Cette amitié, née en se serrant la main physiquement, se serait-elle éteinte avec la dernière main serrée par lettre interposée? Des recherches dans les archives de Marseille n'ont donné aucun résultat concernant la suite de l'amitié et de l'activité épistolaire entre Gabriel Audisio et Pierre André-May après la mort de la revue Intentions.

\section{Alger, Marseille, Maupré et Paris: une périphérie multiple et un centre unique}

8 L'espace géographique couvert par la correspondance de Gabriel Audisio avec Pierre André-May est situé entre, d'une part, un grand pôle politico-culturel, la capitale française, et d'autre part, trois endroits périphériques, Alger, Marseille et Maupré (Saône-et-Loire), marqués, chacun à sa façon, par une relation de dépendance culturelle spécifique face à ce centre unique. C'est à Paris que la revue Intentions est fondée, 
rédigée, imprimée et publiée. C'est là qu'elle est vendue, qu'elle circule, se lit et se discute. C'est là encore qu'elle mourra. C'est à Paris que réside et travaille son directeur et éditeur ; ce sont les milieux littéraires, les librairies, les rédactions de revues et journaux, les grandes maisons d'édition, les théâtres et spectacles parisiens qu'il fréquente. S'il est vrai que tous les maîtres à penser et à écrire, cultivés et vénérés par la revue, -des personnalités comme Paul Valéry, Marcel Proust, Jules Romains, André Gide, Valery Larbaud, Paul Claudel, Léon-Paul Fargue, Saint-John Perse-, ne résident pas tous constamment à Paris, tous pourtant s'y côtoient régulièrement dans les mêmes salons littéraires et temples artistiques, à La Maison des Amis des Livres d'Adrienne Monnier, dans les cafés ou autres lieux publics.

C'est à ce centre culturel par excellence que Gabriel Audisio a dû se rendre pour faire la connaissance de son patron de revue. «Je compte me trouver à Paris dans les premiers jours d'avril ; je pourrai alors faire votre connaissance d'une façon plus effective...», ditil dans une lettre envoyée depuis Alger le 2 mars 1922. La conscience très aiguë de l'énorme distance qui sépare deux mondes qui cherchent à entrer en contact, -le monde dominant de la capitale de toutes les lumières artistiques et celui d'une colonie culturelle périphérique-, s'énonce de façon très claire dans l'exclamation qui ouvre la carte pneumatique envoyée par Audisio à André-May le jour de son arrivée à Paris : «Du fond des Afriques j'arrive.»



La correspondance démarre et s'achève à Alger, capitale de l'Algérie française des années vingt. Elle ne connaît que peu d'autres points de départ : il y a Paris pour les trois messages envoyés lors de la visite d'Audisio à la capitale (première quinzaine d'avril 1922), il y a la ville de Marseille et le village de Maupré (près de Charolles en Saône-et-Loire) pour les six lettres de la seconde quinzaine d'avril et du mois de mai de la même année. Entre juin 1922 et janvier 1925 toutes les lettres et cartes postales partiront d'Alger. 




De nombreux passages commentent les relations culturelles pas toujours simples entre ces lieux périphériques et la capitale. Quelques exemples pris au hasard de la lecture peuvent illustrer la nature de ces relations. En mai 1922 le directeur de la revue a probablement dû écrire, avec des " airs de grand frère ", une lettre (non retrouvée) à son jeune collaborateur (âgé d'un an de plus que lui!), de passage à Marseille après sa visite à Paris, lui reprochant un manque de prudence dans le choix de ses fréquentations artistiques et culturelles, jugées impropres pour un intellectuel de la trempe de Gabriel Audisio. Celui-ci bat humblement sa coulpe dans sa réponse du 24 mai : «Vous avez parfaitement raison quant aux imageries et criées. C'est sans les connaître et pour répondre à l'appel de camarades que je me suis fourvoyé dans ces maisons : mon séjour à Marseille me permet d'avoir une opinion irrémédiable au moins pour l'une des deux! » Aux yeux du directeur d'Intentions, il était impardonnable de collaborer à une revue parisienne haut de gamme et de 'se fourvoyer' en même temps dans des maisons d'éditions et des publications du genre de La Criée marseillaise !

Un minuscule adjectif qualificatif perdu dans une lettre du 28 septembre 1922 dévoile discrètement les formes de tension entre ce qu'on pense à Paris et ce qu'on pourrait oser penser au fond de l'Afrique. A propos de la réaction négative d'André-May à un bref article d'Audisio sur le recueil de son ami Louis Brauquier, Et l'au-delà de Suez, paru dans Le Disque vert du même mois, Audisio demande: " Dites-moi: dans quel sens entendez-vous que mon article sur Brauquier ait été le contraire de ce que vous eussiez écrit ? en tant que chant local ? ${ }^{10}$ " Une voix personnelle, locale, régionale, périphérique: une dissonante dans le concert harmonique et uniformisant de la capitale? Dans ce cas-ci, Audisio se borne à poser la question sans plus. En d'autres occasions, il réfute carrément une argumentation basée sur l'opposition entre ce qui intéresse Paris et ce qui a de l'importance pour la province. Il revendique le droit à une opinion discordante voire dérangeante pour les dieux de l'olympe parisien : « Je vous assure que je ne saisis pas très bien en quoi le 'papier' que je vous avais adressé peut à la fois contenir des choses exactes, mais ne présenter de l'intérêt que pour une revue de province. L'exactitude en soi est la même sous toutes les longitudes de la France et des colonies ; je crois que seuls le déjà dit et la médiocrité foncière s'opposent à la 
publication d'un texte. Ou bien ne faut-il pas faire offense à des dieux très établis, aussi bien en province qu'à Paris, je vous l'assure ? " (lettre du 13 novembre 1922). Malgré cette philippique et véritable apologie pro domo, le 'papier' (un bref texte intitulé L'âge du nègre) envoyé par Audisio et jugé inacceptable par André-May, parce que sans intérêt pour sa revue parisienne, n'a jamais été publié dans Intentions.

13 Audisio propose à plusieurs reprises de chercher pour le directeur de la nouvelle revue des points de distribution aussi bien à Alger qu'à Marseille. Déjà dans sa toute première lettre de février 1922 (envoyée depuis Alger), il écrit : «Voulez-vous ces adresses qui peuvent aider à l'expansion de votre revue? Vous pouvez faire, par réciprocité, le service à «L'Afrique latine» [...] ici même- et à La Criée [...] à Marseille». De la réciprocité avec un distributeur de La Criée: voyons! Il suffit de relire l'opinion du directeur d'Intentions au sujet de cette maison pour comprendre qu'Audisio aura dû chercher quelque chose de plus sérieux : "Je me suis occupé de vous trouver un librairedépositaire dans cette bonne ville. J'ai remis vos conditions à Fuéri et Fouquet [...] qui les accepte mais déclare se contenter au début de deux exemplaires [...]. C'est une maison intéressante, très bien achalandée et qui fait un sort favorable aux revues...», dit-il dans sa lettre du 10 mai 1922. En décembre 1923, Audisio est toujours à la recherche d'un digne dépositaire à Alger : « Soyez sûr que je fais autour de vos Intentions tout le 'bruit' que leur excellence mérite [...]. Faites-donc un dépôt chez Rélin [...], trois exemplaires, par exemple ». Mais la lettre s'achève sur un ton désabusé : " cette ville a si peu de 'rendement' pour ce genre d'ouvrages...». Malgré toutes les démarches et suggestions $\mathrm{du}$ fidèle collaborateur, les très nombreux points de vente, régulièrement publiés dans les numéros d'Intentions, resteront invariablement et exclusivement parisiens et aucune librairie d'aucune des grandes ou petites métropoles périphériques ne figurera jamais dans la liste des libraires-dépositaires de la revue.

\section{Présences et absences de Gabriel Audisio dans Intentions}

14 Gabriel Audisio jouit d'une présence accusée dans Intentions. Son nom se retrouve dans tous les volumes de la revue à partir du numéro 3, de mars 1922 (qui annonce sa prochaine collaboration), jusqu'au dernier numéro (28-29-30) de décembre 1924, une soixantaine de fois au total. On peut distinguer différents degrés dans cette présence. Elle est minimalement assurée par la constante mention de son nom dans la liste alphabétique des collaborateurs, régulièrement publiée sur une des pages de couverture de la revue. Dans d'autres numéros $(13,18,22)$, elle est beaucoup plus marquée : Audisio apparaît comme auteur dans la table des matières, figurant sur la première page de la couverture et au pied du poème, article, note critique, compte rendu ou traduction; il est lui-même l'objet d'une recension d'un de ses livres ou d'autres écrits; il figure dans la section d'information bibliographique ou dans la revue d'autres revues culturelles auxquelles il prête également sa collaboration, pour finalement se retrouver dans la liste des collaborateurs réguliers ornant la couverture postérieure de la revue.

Invité par Pierre André-May à collaborer à sa nouvelle revue par l'intermédiaire d'un ami commun, Jules Romains, Gabriel Audisio enverra d'abord des poèmes tout en envisageant d'emblée de faire parvenir dans les plus brefs délais également « quelque prose critique ». Des deux fois deux " petits poèmes d'une insertion aisée quant aux 
dimensions typographiques » qui accompagnaient les deux premières lettres d'Audisio à la rédaction, un seul sera publié dans la revue : "Amour ", daté du 2 juin 1921 et envoyé avec la lettre du 8 février 1922. $\mathrm{Ni}$ « Hymne » ( sans date ), expédié par la même occasion, ni «Contraste » ni «Escale», suite de deux brefs poèmes, datés de 1922 et remis avec une lettre du 3 mars de la même année, ne verront jamais le jour dans Intentions. Il y eut encore quelques promesses d'envoi d'autres poésies (lettre du 13 novembre 1922) ou de poèmes en prose (novembre 1924) mais le directeur fit la sourde oreille à toutes ces tentatives poétiques. Devant ce silence poli ou refus non avoué, Audisio lui rappellera au moins deux fois l'existence de ses poèmes. Ainsi, dans une lettre du 28 septembre 1922, après lui avoir signalé que la revue Tablettes (de Saint-Raphaël) avait parlé « en termes élogieux » d'Amour, l'unique poème publié dans Intentions, il demande : «Avez-vous conservé les deux ou trois poèmes que vous n'avez pas publiés? » Face au mutisme persistant, il reprendra encore une fois le même thème épineux dans la lettre du 13 novembre de la même année : « Vous devez encore avoir dans vos cartons deux poèmes de moi ; j'aurai plaisir à augmenter ce nombre quand je posséderai des fragments qui puissent subir l'épreuve d'une publication isolée. » Vains envois, vains rappels et vaines promesses : Gabriel Audisio ne participera qu'une seule fois à la revue comme poète.

16 Ce jeu subtil d'offre et de demande, de sélection et de refus, de petits mots et de grands silences, explique les présences visibles mais aussi les absences invisibles de Gabriel Audisio dans les pages d'Intentions. Il illustre également de façon exemplaire les relations sans doute amicales mais aussi très délicates entre un directeur de revue, seul maître à bord et dernier responsable de la ligne et de la qualité de sa publication, et un collaborateur diligent et zélé, vivant loin des grands centres culturels, convaincu de la valeur intrinsèque de son travail et désireux de le voir publié dans un organe d'un certain prestige.

Dans cette difficile recherche d'un équilibre entre deux instances culturelles complémentaires mais de poids forcément inégales, Audisio connaissait parfaitement sa place. C'est ainsi qu'il accepte sans rechigner les petits changements que le directeur lui impose comme, par exemple, l'adaptation ou la suppression d'un titre, ou l'inclusion d'un texte sous telle ou telle rubrique. Voyons cette lettre du 24 avril 1922 : « Je suis satisfait que le papier que je vous avais laissé vous paraisse susceptible d'intéresser une partie de vos lecteurs et puisque vous le publiez dans votre prochain numéro vous avez parfaitement raison de le ranger sous la rubrique "Les idées et les faits", ce qui implique la suppression du titre que j'avais d'abord mis...». En d'autres occasions, le correspondant entre dans les arguments de son éditeur et se range facilement de son avis. Ainsi, en avril 1923, il propose un compte rendu du Traité de versification de Georges Chennevière et Jules Romains : "Dans une brève carte je vous demandais de me laisser le soin de parler du Traité de versification lorsqu'il serait paru. Je maintiens cette requête ! Vous allez me prendre pour un spécialiste de 'Romania'.» Dans sa réponse, André-May a dû lui donner de bonnes raisons pour ne pas publier ce compte rendu, car Audisio écrit le 2 mai suivant : «Ce que vous me dites au sujet du Traité de versification ne me parait pas dénué de fondement du point de vue 'éditorial'. Je me range donc à votre avis.»

18 Face au silence ou au franc refus de publication, il adopte, par contre, différentes stratégies pour essayer de vaincre la résistance. Pour ses poèmes, nous avons vu qu'il se limite à en rappeler régulièrement l'existence. En ce qui concerne ses articles de 
critique littéraire, le premier pas consiste généralement dans l'annonce de l'envoi d'un texte dont il évoque soit l'actualité, soit l'intérêt général, soit des caractéristiques matérielles (brièveté avant tout) ou encore des qualités intrinsèques. Une fois placé devant la négative, il discute ouvertement les arguments apportés par André-May pour étayer son refus, mais il finit en règle générale par céder et accepter la décision du directeur.

Quelques exemples peuvent illustrer cet aspect important de la correspondance et des relations entre les deux intellectuels. Le 14 juillet 1922, Audisio explique à André-May : «...la lecture du dernier roman de J. Romains m'a inspiré les quelques réflexions cijointes. Je sais bien que vous publiez peu de notes relatives à tel ou tel livre, cependant je serais très heureux si vous pouviez faire passer mon article sur Lucienne dans votre numéro d'août...». Cet article n'a jamais été reproduit dans Intentions. Que du contraire : au lieu de publier le texte de son collaborateur spontané, le directeur fera 'passer', sans un mot d'explication, sa propre note de lecture du roman dans le numéro de septembre-octobre 1922. Pour l'article intitulé L'âge du nègre, dont le texte ne se trouve pas parmi les documents conservés, l'histoire du refus final est plus explicite et plus tendue. Dans une carte postale (Alger, 16 octobre 1922), Audisio annonce d'abord son travail: " J'ai un petit article (une ou deux pages de votre format) à tendances légèrement humoristiques sur L'Âge du nègre, essai de classification des influences de la race noire et de recherche des origines de son règne... Le voulez-vous pour les idées et les faits d'un de vos prochains numéros? ». Le 28 octobre, il remet effectivement son texte : «Je vous envoie sous ce pli le petit 'papier' dont il fut question. Je pense que vous pouvez le lire malgré certains 'collages' d'une élégance plus que douteuse. » Nous ignorons les termes exacts de la réponse négative du directeur. Mais la vive réaction d'Audisio à ce refus de publication en dit long sur les arguments invoqués. Nous les avons rapportés plus haut en parlant des tensions entre centre et périphérie. Après la 'défense et illustration' de son propre point de vue, Audisio conclut cependant: " Quoiqu'il en soit, il vous appartient de maintenir votre revue sur telle ligne que vous lui avez assignée et je ne saurais vous en vouloir.» L'affaire était entendue et la discussion ainsi close. Le patron était bel et bien le patron.

Une dernière et bien âpre dissension entre directeur et collaborateur concerne une note de Gabriel Audisio sur Corydon de Gide. Le 15 octobre 1924 il écrit : " Je vous adresse une note sur le Corydon de Gide. Dieu me garde d'être uranien! mais ce bouquin est fort remarquable.» André-May aura refusé net cette note de lecture car le 4 novembre son auteur réplique avec fermeté: «laissez-moi vous dire qu'à mon sens vous faites une erreur (d'ailleurs partagée par beaucoup de ceux qui dans leur cœur jugent Corydon sévèrement) : c'est de recourir à un argument ad hominem. Pour ma part, je me suis interdit en lisant ce livre et en le commentant de mettre devant moi un écran découpé sur le patron de l'auteur même. La question est de savoir si le livre est intéressant 'en soi'. J'ai pensé que oui. Vous pensez que non, sans doute. » La note de Gabriel Audisio sur Corydon, dernier fait d'armes et de lettres du jeune collaborateur d'Intentions à Alger, ne sera évidemment plus publiée dans la revue dont le dernier volume verra le jour précisément au mois de décembre suivant.

21 A part son poème Amour, Gabriel Audisio réussit à 'faire passer' trois articles, quatre comptes rendus et deux traductions dans les différents numéros d'Intentions. Quand on $\mathrm{y}$ regarde de plus près, l'ordre de passage de tous ces travaux n'est nullement arbitraire. La toute première collaboration ( $\mathrm{n}^{\circ} 4$, avril 1922) était poétique. Aucun autre 
poème ne sera publié dans la revue et ce malgré de nombreux rappels. A partir du $\mathrm{n}^{\circ} 5$ (mai 1922) et jusqu'au n 13 (mars 1923), Audisio sera exclusivement l'auteur d'essais critiques, tous rangés sous la rubrique Les idées et les faits. Il publiera successivement : Imagination créatrice et activité physique $\left(\mathrm{n}^{\circ} 5\right)$, L'invention artistique et le milieu extérieur $\left(\mathrm{n}^{\circ}\right.$ 7) et Vision extra-rétinienne et psychologie littéraire $\left(n^{\circ} 13\right)$.

Ces brefs essais démontrent l'intérêt très accusé de leur auteur pour une thématique qui touche aux phénomènes humains situés sur les frontières entre psychologie, philosophie et littérature. Le dernier de ces trois textes est un commentaire mirespectueux mi-amusé d'un livre de Louis Farigoule (le véritable nom de Jules Romains), La vision extra-rétinienne et le sens paroptique. Recherche de psycho-physiologie expérimentale et de physiologie histologique (Paris, NRF, 1920). Dans l'entretemps, comme nous avons vu, un autre essai d'Audisio sur L'Âge du nègre avait été l'objet de discussions avec le directeur de la revue. Le commentaire sur le livre de Farigoule sonnera la fin des essais d'Audisio dans Intentions. Dorénavant il devra se contenter d'un rôle plutôt secondaire, soit comme auteur de brèves notes de lecture ou de comptes rendus, soit comme traducteur de textes d'autrui.

Dans le premier de ses comptes rendus, il manifestera une fois de plus sa fidèle dévotion pour Jules Romains, le pape de l'unanimisme : il consacre en effet une petite note de lecture à la réédition des Odes et prières. Au moment d'envoyer son texte à André-May (lettre du 16 avril 1923), il ne perd pas l'occasion de lui rappeler discrètement que l'article critique et analytique de l'œuvre de Jules Romains qu'il avait publié dans les Écrits du Nord (novembre 1922) "semblait bien avoir donné de la satisfaction "à l'auteur de Knock ou le triomphe de la médecine, appelé ici " notre bon maître ». La note fut promptement publiée dans le numéro suivant d'Intentions (14-15, avril-mai 1923).

Les relations amicales qu'Audisio entretenait avec d'autres écrivains et critiques, tels que Franz Hellens et Jean Hytier, se mesure aussi à l'enthousiasme qu'il montre à l'heure de leur offrir l'une ou l'autre note de lecture, critique certes mais toujours positive. C'est ainsi que dans deux numéros successifs (18, septembre-octobre et 19 , novembre 1923), il publiera un compte rendu d'abord du volume Réalités fantastiques de Hellens et ensuite de la thèse universitaire Le plaisir poétique de Jean Hytier. Le premier de ces deux textes semble avoir été écrit sur invitation d'André-May, le deuxième à sa propre initiative. Le 2 mai 1923, Audisio fait savoir à son directeur : " Des éditions du Disque Vert je n'ai que 'Notre-Mère la ville' et 'Réalités fantastiques'. Ce dernier volume m'a vivement intéressé, mais je ne puis vous affirmer que j'aurais quelque chose de valable à en dire, ce qui n'engage pas du tout la valeur de l'ouvrage ». A la fin du mois d'août, il revient sur le même sujet : «J'ai rédigé la note sur le livre de Hellens, je vais la recopier et vous l'envoyer. » Et de poursuivre : «Dites-moi sans retard si vous acceptez ma note sur le livre d'Hytier pour votre numéro de novembre? Elle irait, je crois, très bien dans votre revue. [...] Ça pourrait même trouver place à votre rubrique des 'Idées et des Faits'. Qu'en pensez-vous ? " André-May accepte la suggestion de son collaborateur zélé qui enverra ensuite son texte avec une lettre du 22 novembre $1923:$ «Je vous envoie sous ce pli ma note [...] sur l'ouvrage d'Hytier [...]. Je vous ai réservé celle-ci : vous m'obligeriez donc en ne la retardant pas trop. " La note fut publiée en novembre, pas dans la rubrique suggérée, disparue dans l'entretemps, mais plus modestement entre les notes de littérature générale. 

Elle se rapporte à un volume de récits de voyage de Jean-Richard Bloch : Sur un cargo. A la découverte du monde connu. La note de lecture accompagnait une lettre du 9 juillet 1924 : «Je vous envoie une note sur le livre de Jean Richard Bloch; il n'est sans doute pas trop tard pour qu'elle puisse paraître dans un numéro d'Intentions avant la rentrée; vous avez peut-être même un numéro de juillet en préparation? Aimez-vous ce livre autant que je fais? » La note fut effectivement reprise dans le dernier volume de la revue avant les grandes vacances de l'année 1924. Ensuite Audisio disparaît d'Intentions comme créateur et critique littéraire. Seul son nom survit dans la liste traditionnelle des collaborateurs. Aucun de ses poèmes restés dans les cartons du directeur, ni sa note ardemment défendue sur Corydon, ni son texte perdu sur un essai de Marthe Esquerré, ni le compte rendu conservé sur Plainte contre inconnu de Pierre Drieu La Rochelle et Une création du monde de nos jours de Pierre Sichel, papier appelé humoristiquement « D'un coup deux Pierre »! (lettre du 14 novembre 1924), ni les «quelques pages en prose» non conservées mais envoyées le 24 novembre de la même année, n'ont finalement été publiés dans Intentions. Un texte fut passé sous silence, l'autre fut carrément refusé, un troisième aura soulevé des doutes, et le reste sera arrivé trop tard pour pouvoir encore sauver la revue d'une mort subite.

\section{Les bonnes «intentions» d'un apprenti d'écrivain}

Dès sa première prise de contact avec la revue nouveau-née Intentions (février 1922), jusqu'à sa disparition inattendue (janvier 1925), Gabriel Audisio, poète et critique littéraire en herbe, fera constamment preuve, dans ses différentes formes de collaboration, aussi bien de beaucoup d'enthousiasme et d'une parfaite loyauté que d'une extrême rigueur dans le travail et d'un sens critique aigu. Dans sa toute première lettre à Pierre André-May, à ce moment-là quelqu'un de parfaitement inconnu pour lui, il déclare : "J'ai pris contact, non sans satisfaction, avec vos 'Intentions' qui se présentent fort bien. C'est avec plaisir que je m'associerai à vos efforts. » Comme je l'ai signalé plus haut, il lui envoie sans tarder quelques poèmes inédits. Tout au long des trois années de vie de la 'petite revue', il n'aura de cesse d'offrir ses bons services et ses textes. Un exemple parmi d'autres. Le 10 mai 1922, quelques semaines à peine après sa première rencontre avec André-May à Paris, il écrit: «Si ma collaboration continue à vous être de quelque agrément, ne vous gênez pas pour me suggérer tel travail qui vous paraitrait opportun...». Et d'ajouter avec une pointe d'humour, trait caractéristique de son style épistolaire : «Je pourrais toujours vous répondre que 'ça n'est pas dans mon tempérament' (ce qui arrive généralement dans ces cas !)...».

On peut déduire des pièces de correspondance conservées qu'à un moment donné, plus précisément lors de leur rencontre dans la capitale française, Audisio a dû suggérer à André-May de participer d'une manière plus active, plus structurelle ou plus matérielle à la rédaction voire même à la direction de la revue. Dans sa lettre du lundi 10 avril 1922, il dit: «J'aimerais beaucoup vous voir et vous parler de nouveau assez longuement et vous faire part de quelques intentions au sujet de celles que vous dirigez.»

Dès le début, il associe son ami Jean Hytier à ses bonnes 'intentions' et à son initiative de collaboration. Le 20 avril 1922, tout de suite après son départ de Paris, il explique, depuis la résidence de son ami à Maupré : « Je suis ici en la compagnie de Jean Hytier avec qui j'ai bavardé assez longuement au sujet de ce que je vous avais suggéré quant à

Bulletin d'Histoire Contemporaine de l'Espagne, 54 | 2020 
la revue.» Un mois plus tard toutefois, l'idée d'une participation plus directe à la revue doit être abandonnée. Il l'annonce dans les termes suivants : « Peut-être savez-vous déjà que Jean Hytier [...] réalise son projet de revue ? Voilà qui m'empêchera sans doute de vous reparler du projet de participation auquel j'avais songé [...]». En effet, Hytier allait fonder en septembre de cette même année la revue le Mouton Blanc, dont il sera le rédacteur en chef et à laquelle Audisio collaborera régulièrement. Ce virage soudain et inattendu dans les pourparlers n'affectera pourtant pas leurs relations même si le directeur d'Intentions a pu avoir un jour l'impression que Jean Hytier « nourrît des sentiments sans tendresse " à son égard (lettre 30). Au contraire, Audisio lui réaffirme son amitié et sa gratitude : "Mais il va de soi que j'ai trouvé 'chez vous' une trop bonne cordialité dans l'accueil, pour me tourner entièrement d'un autre côté. A ce propos j'aimerais continuer une série d'essais dans le genre de celui que vous avez donné dans votre dernier numéro ». Et de conclure sur une véritable déclaration d'amour : «D'ailleurs j'aime beaucoup Intentions et lui donnerais volontiers une collaboration suivie pour quelque rubrique qui vous paraîtrait opportune.» Les propos parfois très critiques, la sévère sélection et le fréquent refus d'André-May mettront un sérieux frein aux ardeurs enthousiastes d'Audisio. Qu'importe : le fidèle collaborateur continuera à envoyer imperturbablement des textes et à faire l'éloge des numéros successifs de la revue.

Gabriel Audisio a pu faire son entrée dans la revue Intentions grâce à son amitié avec le chef de file du mouvement unanimiste, Jules Romains. "Des relations nouées par l'intermédiaire de Jules Romains sont pour moi garantes de solidité et de valeur ", affirme-t-il dans sa première lettre du 8 février 1922. Ce sera ensuite sur un même fond d'amitié et invoquant le même ou d'autres grands noms, qu'à son tour Audisio essaiera de faire entrer ses propres bons amis. Déjà en mars 1922 il propose Louis Brauquier : «Voulez-vous prendre en note le nom d'un de mes grands amis, fraternel comme l'est Jean Hytier que vous connaissez de nom? Il s'agit de Louis Brauquier, qui écrit des vers fiévreux et ensoleillés. Je me permets de lui dire de vous écrire au cas où sa collaboration vous agréerait. " Malgré cette forte recommandation et l'éloge de son œuvre, aucun de ses poèmes ne fut jamais reproduit dans la revue. La même chose passe avec un autre bon ami du Midi, le poète Francis Ponge. Dans un carton envoyé pendant son bref séjour à Paris en avril 1922, il écrit: «...je vous signale le nom d'un bon camarade à qui vous pourriez demander, si vous le jugez bon, quelques lignes -prose ou vers. Il s'agit de Francis Ponge. [...] Jules Romains le connaît de nom et le croit digne d'intérêt, - je vous le livre derrière ce grand nom qui nous est cher.» Démarche inutile. Ni le 'grand nom' de Jules Romains, ni la recommandation de Gabriel Audisio, ni les qualités intrinsèques de l'œuvre littéraire de Ponge ne parviendront à convaincre le directeur et jamais aucun vers du célèbre poète ne paraîtra dans Intentions.

Tout ceci nous ramène encore une fois au subtil chassé-croisé entre les présences et les absences d'Audisio dans la vie de la revue parisienne, sur un arrière-fond complexe de stratégies d'exclusion et d'inclusion, entre un centre culturel hégémonique et une périphérie multiple et diversifiée. A ce propos, il faut revenir encore un instant sur le vaste réseau littéraire et culturel évoqué par la correspondance et auquel Audisio avait accès comme collaborateur de la revue. Il y a d'abord le cercle des grands noms déjà cités, les maîtres avoués et vénérés d'Intentions, tels que Jules Romains et sa cour unanimiste (Georges Chennevière, Marthe Esquerré, D.O.Mannoni...), Gide, Valéry, Claudel, Valery Larbaud, Proust, Fargue, Saint-Paul Roux... Ils sont l'objet de fréquents éloges et de félicitations de la part du jeune critique. Déjà dans sa lettre du 2 mars 1922, 
il déclare : « Je n'ai pas encore en mains le dernier fascicule, mais j'ai plaisir à voir l'empressement des grandes collaborations dont vous vous entourez. " Sa lettre du 10 mai 1922 montre clairement l'effet 'bienfaisant' qu'avait eu, aussi bien pour le développement de son goût esthétique que pour ses relations socio-littéraires, un long fragment de texte de Proust, publié dans le numéro 4 d'Intentions. Il déclare : « Marcel Proust vous a gâté et -réjouissez-vous- m'a fait un effet tel que je me sens apte désormais à l'aller quérir partout avec bonne volonté et une satisfaction certaine !»

Un dernier exemple de cette vénération pour les tout grands noms du monde culturel français de l'après-guerre se lit dans une lettre du 27 novembre 1922, écrite après réception du numéro d'hommage à Valery Larbaud (avec des collaborations, entre beaucoup d'autres, de Ch. Du Bos, L.P. Fargue, J. Giraudoux, R. Gómez de la Serna, Edm. Jaloux, P. Morand, J .Romains, Saint-John Perse): « Merci pour le numéro de novembre. La personnalité à qui l'on y rend hommage est de celles qui entraînent l'admiration. Vous avez des collaborations nombreuses et brillantes. Tous mes compliments. C'est très bien. "

Un deuxième cercle dans le vaste réseau culturel auquel Audisio participe, est formé par ses contacts suivis ou occasionnels avec de nombreuses autres revues littéraires, maisons d'édition ou auteurs étrangers. Parmi les revues citées figurent Accords (fondée par André Desson et André Harlaire), Signaux de France et de Belgique, le Disque vert et Ecrits du Nord, la saga inextricable des revues de Franz Hellens, les Ecrits Nouveaux (d'André Germain), les Nouvelles Littéraires (de Maurice Martin du Gard), le Mouton Blanc (de son ami Jean Hytier), désigné à plusieurs reprises comme le 'candide ovin' et cité sous ses lettres initiales MB, la célèbre Revista de Occidente de José Ortega y Gasset ou la très populaire La Criée de Marseille.

Le côté hispanisant d'Audisio se manifeste de temps à autre, par exemple dans ses commentaires sur des textes de Miró (traduits par Valery Larbaud), dans son intérêt à voir publiées ses traductions de contes d'Alfonso Reyes, dans son adhésion à la note de protestation contre l'exil de Miguel de Unamuno, et surtout dans sa participation comme traducteur au numéro spécial sur 'la jeune littérature espagnole'. Dans le troisième cercle de ses relations culturelles (cercle le plus éloigné du centre parisien), on retrouve des amis plus intimes comme Louis Bauquier ou Francis Ponge. J'ai montré comment Gabriel Audisio s'efforce, souvent sans succès d'ailleurs, à les faire entrer dans le monde fermé et élitaire des dieux et demi-dieux.

Des références à sa propre œuvre littéraire, poétique et critique, ne manquent pas non plus dans la correspondance retrouvée du jeune écrivain. Déjà dans sa toute première lettre au directeur d'Intentions, quand il lui promet sa collaboration à la nouvelle revue, il lui confie aussi que malheureusement un livre en préparation ne lui laissera que peu de temps libre: «Je me réserverai sans aucun doute de vous faire parvenir quelque prose critique, dès que la mise au point d'un volume sur le chantier me laissera plus de libertés.» Il s'agit de son premier recueil de poésie, Hommes au soleil. Les nombreux avatars de son édition seront un thème récurrent dans plusieurs lettres entre le mois de mai 1922 et l'automne 1923, quand les éditions du Mouton Blanc, dirigées par son ami Jean Hytier, le publient finalement. Le report constant de sa parution était devenu à la longue une source d'ironie et de bons mots. Voyons par exemple ceci dans sa lettre du 2 mai 1923 : « Je pense vous annoncer bientôt la parution de mes pauvres Hommes au soleil, à l'ombre depuis si longtemps. On ne se presse guère aux éditions du candide ovin qui s'en charge !» En août, il commente : «J'ai corrigé les épreuves de mon bouquin qui 
est sous presse et va enfin sortir! J'en donnerai sans doute un autre cet hiver ». Il se réfère ici à son second recueil de poésie, Poème de la joie, édité à Paris cette fois-ci, en 1924, à la Maison des Amis des Livres. En vue d'une plus large publicité, il demande (lettre du 13 mars 1924) à son directeur de revue de placer une petite annonce : «Puis-je vous demander un service ? Ces jours-ci sera achevé d'imprimer un petit livre de vers que 'j'édite' moi-même sans aucune firme. Je crains qu'il ne passe un peu inaperçu. Pouvezvous, si cela est possible, insérer une annonce dans les pages d'Intentions ?». L'annonce fut publiée dans le $\mathrm{n}^{\circ}$ de mars 1924.

Pour compléter le portrait trop rapidement esquissé du jeune intellectuel Gabriel Audisio, tel qu'il se fait connaître dans sa correspondance avec Pierre André-May, il ne reste plus qu'à souligner la qualité, la rigueur et la maturité de son esprit critique en matière de littérature et esthétique. J'ai déjà mis en évidence l'étonnante assurance et l'âpreté de ses opinions lors des discussions sur le contenu de tel ou tel de ses articles théoriques ou sur la valeur de tel ou tel auteur ou livre recensé. Les divergences de jugement s'enveloppent au début de formules très polies et pleines de déférence. Au fur et à mesure que les relations deviennent plus ouvertes, les distances se marquent de plus en plus. Vers la fin de leurs relations épistolaires, Audisio en arrive à dire tout haut et sans ambages qu'André-May se trompe et que leurs positions critiques respectives s'excluent mutuellement. Ainsi, au sujet de Corydon d'André Gide, il écrit: «...laissez-moi vous dire qu'à mon sens vous faites une erreur (d'ailleurs partagée par beaucoup...). [...] La question est de savoir si le livre est intéressant 'en soi'. J'ai pensé que oui. Vous pensez que non ».

Le même sens critique se retrouve face à des textes publiés dans la revue elle-même. Le jeune collaborateur, toujours empressé de faire l'éloge de la petite revue et de ses grands collaborateurs, n'hésite pourtant pas de manifester de temps à autre ses réticences. Voici un exemple éloquent. Après avoir reçu et lu, probablement en compagnie de Jean Hytier, le numéro d'avril 1922, dans lequel figurait son propre poème Amour, il commente : «Le numéro 4 est vraiment bien réussi, sauf peut-être les deux dernières pages? Rassurez-vous ! ce n'est pas tant à moi-même que je pense, qu'à la place occupée par Marcel Proust et à l'excellent esprit de l'article de O.Mannoni...». Proust venait de publier un long fragment Etrange et douloureuse raison d'un projet de mariage, extrait de Sodome et Gomorrhe. Mannoni faisait dans son article L'Unanimisme une présentation bienveillante et une analyse théorique du mouvement. Les deux pages poliment rejetées reproduisaient deux poèmes appelés 'plastiques', La Belle Gueuse et Les gerbiers de Roger Frène, pseudonyme du poète aveyronnais Roger Fraysse (Rodez, 1878 - Vimenet, 1939).

37 La rigueur philologique, cette attention extrême à la précision textuelle et à la bonne présentation graphique de ses écrits, est une autre démonstration de l'esprit critique du jeune Audisio. Redoutant probablement les négligences habituelles des éditeurs, il ajoute un post-scriptum à sa toute première lettre (avec laquelle il envoie quelques poèmes): «Je vous abandonne le soin de veiller à la correction des épreuves.» Après la publication de son poème Amour dans le numéro d'avril 1922, il réagit vivement : «J'ai reçu les quatre exemplaires d'Intentions; je vous remercie de cet envoi rapide [...]. Malheureusement je déplore la coquille qui m'a fait dire villages au lieu de sillages: c'est fort ennuyeux, car on peut s'y tromper, et à mon désavantage.» (lettre du 20 avril 1922). Contrairement à ce que craignait le poète, les lecteurs semblent avoir apprécié l'originalité de la 'mauvaise' version de son poème! Il commente le cas avec beaucoup 
d'humour (une preuve supplémentaire de son sens critique) dans sa lettre du 28 septembre 1922: «... Hytier me fait part que Les Tablettes ont signalé mon poème Amour en termes élogieux et particulièrement l'image du début qui repose -vous vous en souvenez?- sur une coquille! La foi! Elle est très bonne ».

Dans une lettre antérieure (21.06.1922), il avait déjà raconté à Pierre André-May une autre mauvaise surprise. Il s'agissait de ses poèmes publiés par Franz Hellens: «C'est vous qui m'avez fait connaître l'insertion de mes poèmes dans Le Disque vert [...]. Les deux premiers numéros viennent de me parvenir : on m'a fait de jolies coquilles ! Provence, province! orthographe, et surtout on a réuni sous le titre " Poissonneries " (I et II) deux poèmes qui n'ont rien à voir l'un avec l'autre. Je vous dis ça pour vous permettre de rétablir le texte dans sa 'pureté' native ». Suite à ces différentes expériences négatives quant à la précision textuelle, Gabriel Audisio va insister régulièrement sur la nécessité de lui envoyer des épreuves afin d'éviter d'autres dégâts textuels (voir les lettres 8,12,19, 20...).

39 On comprend facilement que le jeune critique Audisio, ami lointain d'André-May et collaborateur bien intentionné de sa revue, apprendra la nouvelle inattendue de la mort de la publication parisienne avec beaucoup de regret et avec une douleur sincère. Dans son dernier message conservé, il déclare : «Votre lettre [...] me navre. Ainsi Intentions à son tour disparaît ? C'est tout à fait malheureux. J'avais pu croire que cette excellente petite revue était définitivement 'partie'; elle avait sa place bien à elle. On la regrettera. »

Trois ans de correspondance suivie avec Pierre André-May et une fidèle collaboration à l'excellente petite revue' parisienne Intentions, nous font connaître le jeune marseillais Gabriel Audisio comme intellectuel et critique littéraire plutôt que comme poète. Nous le voyons se mêler, depuis sa lointaine et coloniale retraite africaine d'Alger, aux débats qui, au début des années vingt, agitent une grande partie du monde littéraire et culturel d'un grand centre européen, tiraillé entre la tradition classique et les innombrables mouvements d'avant-garde qui prétendent à la modernité. Ce fidèle admirateur et disciple de l'unanimisme à la Jules Romains, parviendra à se forger au fil des années un visage bien à lui. C'est précisément dans sa correspondance avec le directeur d'Intentions et dans ses textes critiques que nous pouvons assister à ses premières prises de position esthétiques et idéologiques. 'Homme de soleil' et de mer, nourri aussi bien d'une large culture occidentale que d'histoire et de tradition nordafricaine, il s'avance, déjà dans les années 1922-1925, comme un ardent défenseur de la culture méditerranéenne dans toute sa variété et richesse, face aussi bien à l'algérianisme régionaliste ambiant qu'au colonialisme borné ou à l'hégémonie de la métropole.

41 Après la lecture de cette petite quarantaine de lettres, on ne sera nullement étonné de retrouver Gabriel Audisio plus tard en France, dans les années 1935 à 1950, parmi les représentants les plus significatifs de ce qu'on appelle L'Ecole d'Alger, en compagnie de ses 'cousins du soleil', Albert Camus, Emmanuel Roblès, Max-Pol Fouchet, René-Jean Clot ou Mouloud Feraoun. L'énorme intérêt qu'Audisio manifeste dans sa correspondance pour la culture littéraire et pour le monde de l'édition et des revues, l'orientera plus tard presque naturellement vers des personnages et des institutions tels qu'Edmond Charlot et sa librairie Les vraies richesses, ou vers des revues plus générales ou plus strictement culturelles qui prenaient la défense de la tradition méditerranéenne dans le sens le plus large du terme. Personne ne s'étonnera non plus 
de voir ce jeune chef de service du Gouvernement Général d'Alger dans les années vingt, jouer, -après les épreuves de la guerre, de la résistance et de la captivité-, un rôle officiel de premier ordre dans les relations littéraires et culturelles entre la France et l'Algérie.

\section{CORRESPONDANCE}

\section{Gabriel AUDISIO à Pierre ANDRÉ-MAY}

\section{(1922-1925)}

\section{1}
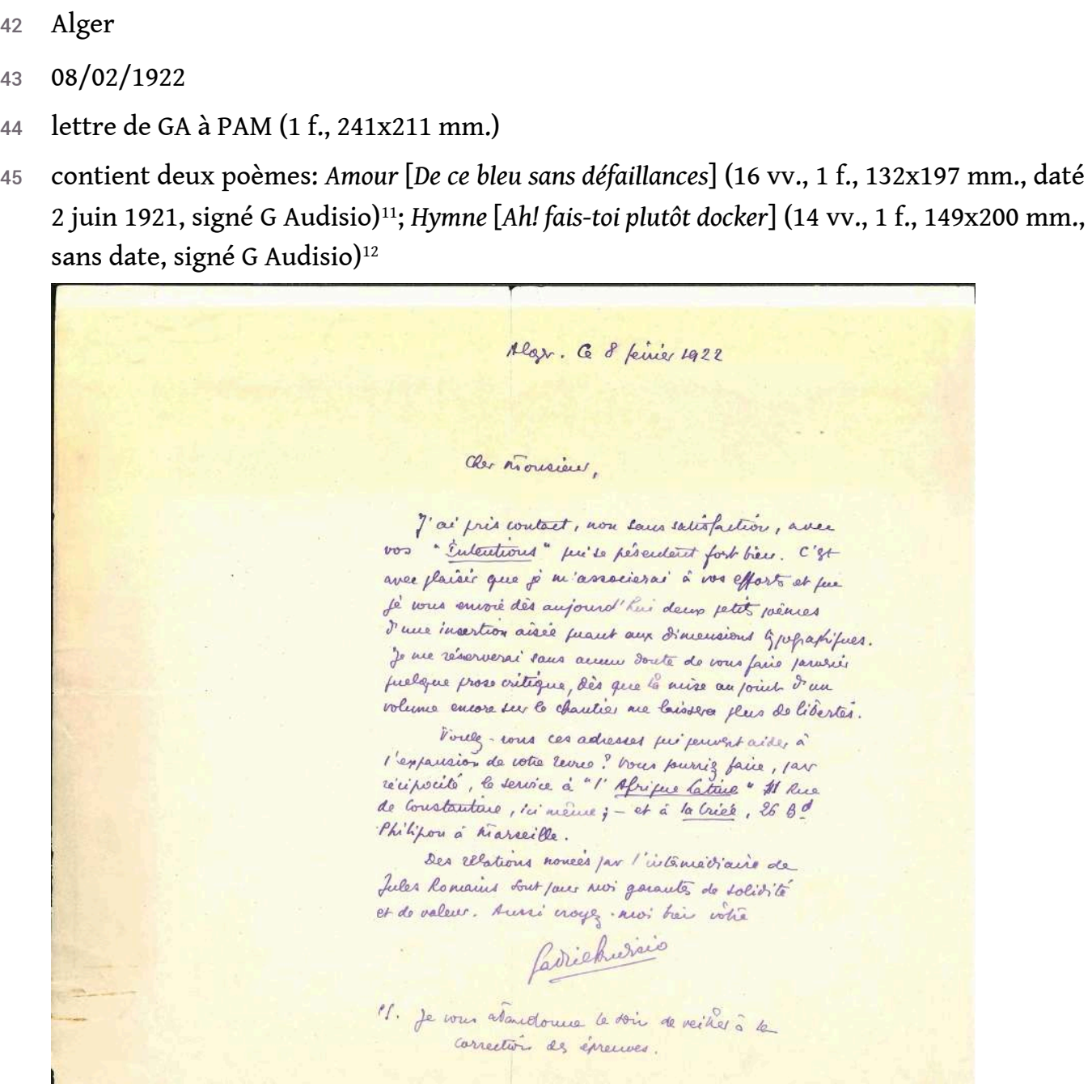

Alger. Ce 8 février 1922

Cher Monsieur,

J'ai pris contact, non sans satisfaction, avec vos «Intentions» qui se présentent fort bien. C'est avec plaisir que je m'associerai à vos efforts et que je vous envoie dès aujourd'hui deux petits poèmes d'une insertion aisée quant aux dimensions typographiques. Je me 
réserverai sans aucun doute de vous faire parvenir quelque prose critique, dès que la mise au point d'un volume encore sur le chantier ${ }^{13}$ me laissera plus de libertés.

Voulez-vous ces adresses qui peuvent aider à l'expansion de votre revue? Vous pourriez faire, par réciprocité, le service à «L'Afrique Latine» ${ }^{14}, 41$ Rue de Constantine, ici même; - et à La Criée, ${ }^{15} 26 \mathrm{Bd}$ Philipon à Marseille.

Des relations nouées par l'intermédiaire de Jules Romains sont pour moi garantes de solidité et de valeur. Aussi croyez-moi bien vôtre

(sign.) Gabriel Audisio

P.S. Je vous abandonne le soin de veiller à la correction des épreuves.

2

Alger

$02 / 03 / 1922$

carton de GA à PAM (1 f., 117x90 mm.)

accompagné d'un feuillet (320x212 mm.) plié en deux formant un cahier, daté 1922, signé Gabriel Audisio sur la première face, et qui contient deux poèmes ${ }^{16}$ : 1 .Contraste [Les deux mosquées, l'Amirauté] (12 vv., 153x219 mm., signé GA.); 2. Escale [Le pavillon traînant au ras de l'eau] (13 vv., 156x 211 mm., signé GA.)

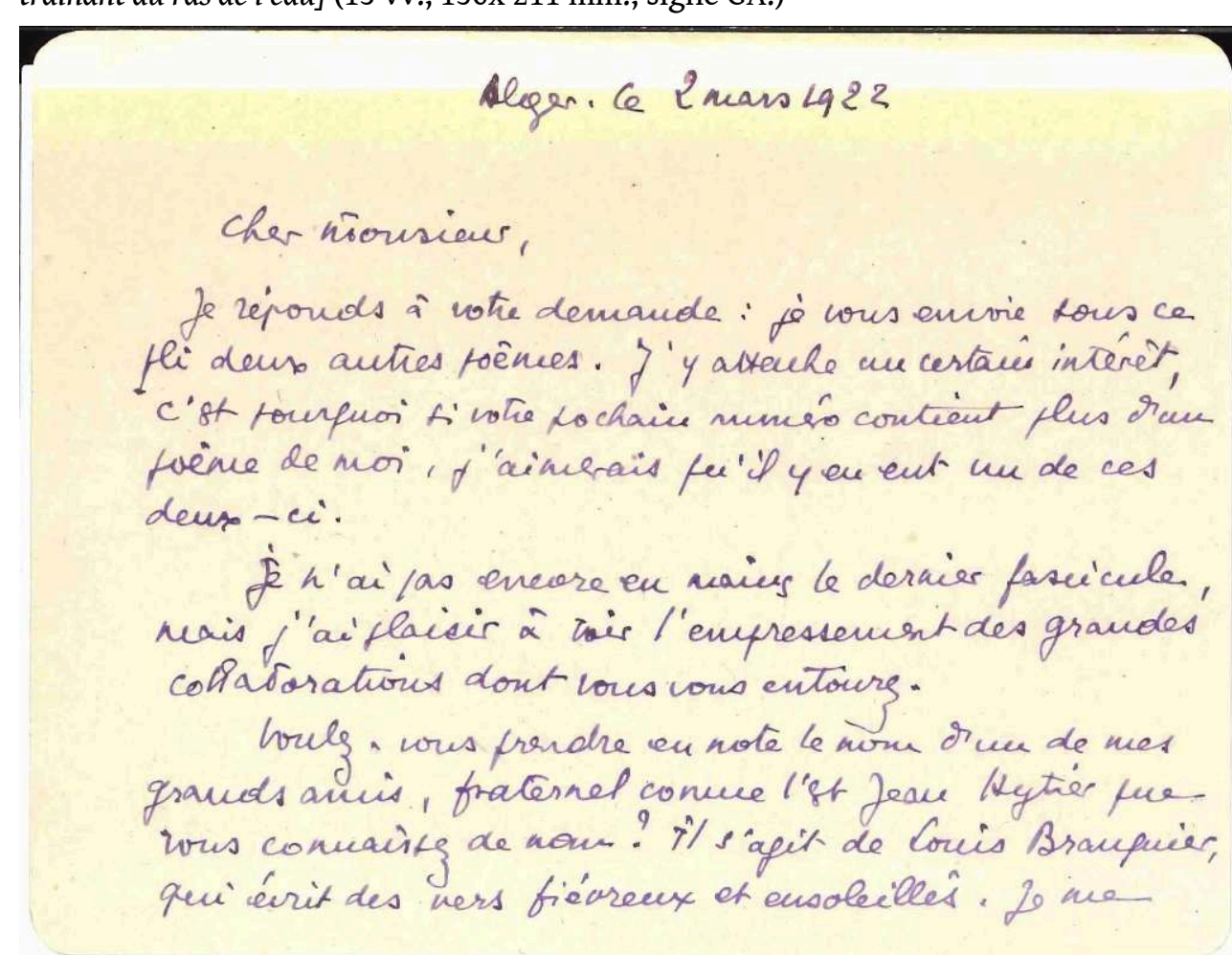


Alger. Ce 2 mars 1922

Lermes de hie bire de cous écrire aucas ori sa collabo-

- ration cous agrêerait.

- Ie confie ne tomuer â Paris dous les prniers

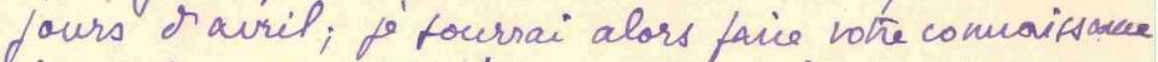

Inve /ajon flus effective, et non novis corosicle

fue ce four

Bien i cout



Cher Monsieur,

Je réponds à votre demande: je vous envoie sous ce pli deux autres poèmes. J'y attache un certain intérêt, c'est pourquoi si votre prochain numéro contient plus d'un poème de moi, j'aimerais qu'il y en eût un de ces deux-ci.

Je n'ai pas encore en mains le dernier fascicule, mais j'ai plaisir à voir l'empressement des grandes collaborations dont vous vous entourez.

Voulez-vous prendre en note le nom d'un de mes grands amis, fraternel comme l'est Jean Hytier ${ }^{17}$ que vous connaissez de nom? Il s'agit de Louis Brauquier ${ }^{18}$, qui écrit des vers fiévreux et ensoleillés. Je me permets de lui dire de vous écrire au cas où sa collaboration vous agréerait.

Je compte me trouver à Paris dans les premiers jours d'avril; je pourrai alors faire votre connaissance d'une façon plus effective, et non moins cordiale que ce jour.

Bien à vous

(sign.) Gabriel Audisio

\section{3}

[Paris]

mercredi $17 \mathrm{~h}$ [05/04/1922] (date des trois cachets de la Poste)

carte pneumatique (numérotée 17) de GA à PAM (1 f., 112x143 mm.) avec double cachet du bureau d'envoi de la Poste «Paris $68 \mathrm{Bd}$. Rochechouart» et simple cachet du bureau de réception «Paris [?]», expédiée par «Audisio, demeurant à Rue ND Lorette $n^{\circ}$ 54» 

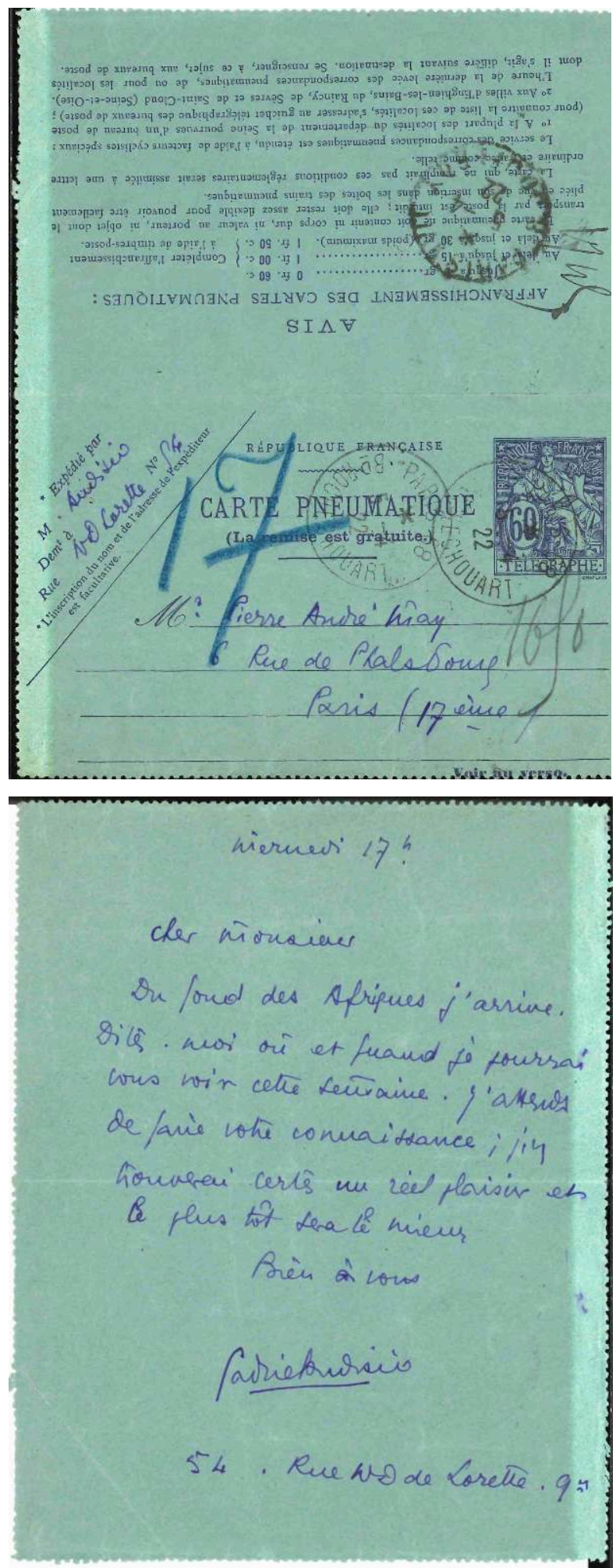

\section{Mercredi $17 \mathrm{~h}$}

Cher monsieur

$\mathrm{Du}$ fond des Afriques j'arrive. Dites-moi où et quand je pourrai vous voir cette semaine. J'attends de faire votre connaissance; j'y trouverai certes un réel plaisir et le plus tôt sera le mieux 
71

\section{4}

74 de celles que vous dirigez.

80 bref est si rempli que je pousserais volontiers la tyrannie jusqu'à vous demander ${ }^{19}$
d'accepter mon horaire!

81 Excusez-moi et en attendant de vous voir, très cordialement à vous de

82 (sign.) Gabriel Audisio

8354 , Rue N[otre]-D[ame] de Lorette

5

84 [Paris]

85

86 signale le nom d'un bon camarade à qui vous pourriez demander, si vous le jugez bon, quelques lignes - prose ou vers. Il s'agit de

mercredi soir [12/04/1922]

carton de GA à PAM (1 f., 117x 90 mm.)

Mercredi soir

Mon cher Ami

Avant de quitter Paris, -et en me réjouissant à nouveau de vous avoir connu,- je vous Francis Ponge ${ }^{20}$. 57. Rue de Seine à Paris VIe

Jules Romains le connaît de nom et le croit digne d'intérêt, - je vous le livre derrière ce grand nom qui nous est cher.

A plus tard de vos nouvelles et croyez-moi toujours prêt à réaliser avec vous les plus probes efforts.

Bien cordialement

(sign.) Gabriel Audisio

\section{6}

95 

de précis à vous communiquer bientôt. En tous cas recevez dès aujourd'hui les salutations d'Hytier et croyez à mes sentiments très cordiaux

111 Vôtre

112 (sign.) Gabriel Audisio

\section{8}

113 Maupré [Charolles, Saône-et-Loire]

114 24/04/1922 le publiez dans votre prochain numéro vous avez parfaitement raison de le ranger sous 
la rubrique «Les idées et les faits», ce qui implique la suppression du titre que j'avais d'abord mis et qui n'avait somme toute qu'une valeur de repère pour moi-même ${ }^{26}$.

Seulement... soyez assez aimable pour m'envoyer les épreuves, si cela est possible bien entendu.

Le numéro 4 est vraiment bien réussi, sauf peut-être les deux dernières pages ${ }^{27}$ ? Rassurez-vous! ce n'est pas tant à moi-même que je pense ${ }^{28}$, qu'à la place occupée par Marcel Proust ${ }^{29}$ et à l'excellent esprit de l'article de $0 . M a n n o n i{ }^{30}$ qui est décidément bien celui que je connus au Centre d'Etudes de Strasbourg.

A vous lire et croyez à ma bonne amitié

(sign.) Gabriel Audisio

P.S. Etes-vous au courant de la marche des Signaux de Franz Hellens ${ }^{31}$ ? Leur parution at-elle repris?

124 Je vous aviserai de mon changement d'adresse qui aura lieu sans doute dans les premiers jours de mai, où je serai

27. Allées de Meilhan à Marseille.

9

Marseille

02/05/1922

lettre de GA à PAM (1 f., 111x183 mm.) sous pli du Café Riche à Marseille (cachet de la Poste Marseille-Capucines Bouches du Rhône, 3/5/22)






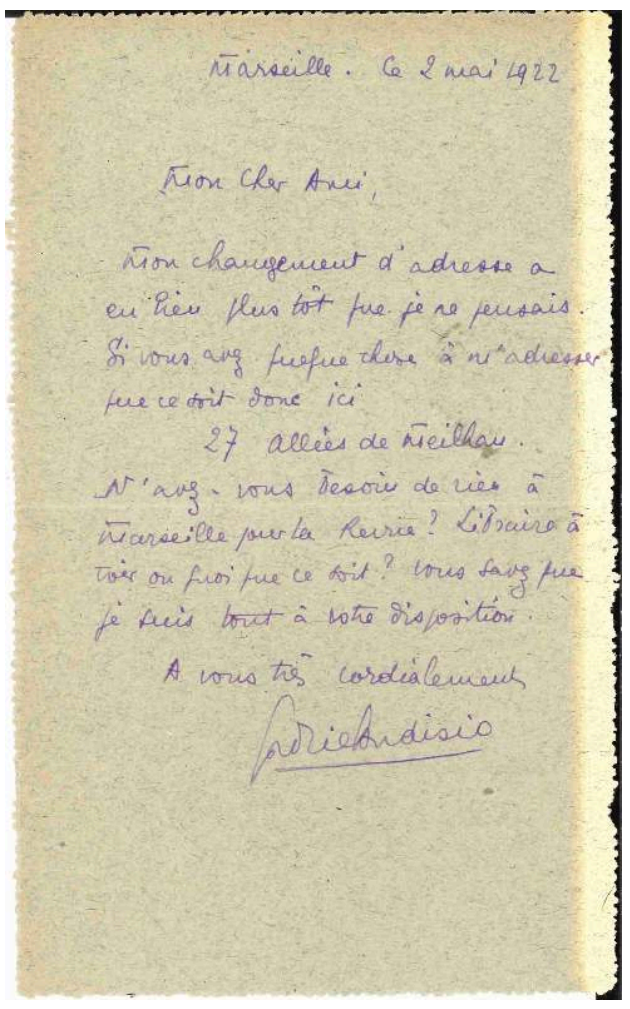

Marseille. Ce 2 mai 1922

Mon cher Ami,

Mon changement d'adresse a eu lieu plus tôt que je ne pensais. Si vous avez quelque chose à m'adresser que ce soit donc ici

27 Allées de Meilhan.

N'avez-vous besoin de rien à Marseille pour la Revue? Libraire à voir ou quoi que ce soit? Vous savez que je suis tout à votre disposition.

$A$ vous très cordialement

(sign.) Gabriel Audisio

10

Marseille

$10 / 05 / 1922$

lettre de GA à PAM ( $1 \mathrm{f} ., 215 \times 273)$

Marseille. Ce 10 mai 1922

Cher Ami,

Je me suis occupé de vous trouver un libraire-dépositaire dans cette bonne ville. J'ai remis vos conditions à Fuéri et Fouquet (21. Rue Paradis) qui les accepte mais déclare se contenter au début de deux exemplaires pour éviter des frais de réexpédition au cas de faible vente. C'est une maison intéressante, très bien achalandée et qui fait un sort favorable aux revues dans sa vitrine. - Si vous avez besoin de quelque autre démarche, mettez-moi à contribution. 
142 J'attends votre numéro de mai. - Dans le dernier, Marcel Proust vous a gâté ${ }^{32}$ et réjouissez vous- m'a fait un effet tel que je me sens apte désormais à l'aller quérir partout avec bonne volonté et une satisfaction certaine!

Si ma collaboration continue à vous être de quelque agrément ne vous gênez pas pour me suggérer tel travail qui vous paraîtrait opportun; je pourrais toujours vous répondre que «ça n'est pas dans mon tempérament» (ce qui arrive généralement dans ce cas!) et ce serait toujours un profitable criterium.

Croyez à ma sympathie très cordiale et qu'il me soit encore donné de vous lire.

Bien vôtre

(sign.) Gabriel Audisio

\section{1} de revue ${ }^{38}$ ? Voilà qui m'empêchera sans doute de vous reparler du projet de participation auquel j'avais songé et que je vous avais suggéré au cours de ma dernière visite à Paris. Mais il va de soi que j'ai trouvé «chez vous» une trop bonne cordialité dans l'accueil pour me tourner entièrement d'un autre côté. A ce propos j'aimerais continuer une série d'essais dans le genre de celui que vous avez donné dans votre dernier numéro ${ }^{39}$ : y trouverez-vous un intérêt suffisant? D'ailleurs j'aime beaucoup Intentions et lui donnerais volontiers une collaboration suivie pour quelque rubrique qui vous paraîtrait opportune. 
12

\section{3}




\section{4}

179 Alger

\section{5}

A bientôt le plaisir de vous lire,

et très cordialement à vous de

(sign.) Gabriel Audisio

28/09/1922

lettre de GA à PAM (1 f., 216x254 mm.)

Alger. Ce 28 septembre 1922

Cher Ami

Merci de votre carte. Il y avait assez longtemps que nous ne nous étions plus donné de nouvelles. Je pense que vous avez «dépensé» de joyeuses vacances et que vous allez rentrer à Paris plein d'une ardeur qui confirmera vos intentions. J'attends votre numéro d'octobre, et j'aurai plaisir à vous voir célébrer Valery Larbaud ${ }^{51}$ pour qui j'ai de vraies tendresses.

5 J'ignorais le «retentissement» de l'article que je vous avais donné52! Par le même courrier, Hytier me fait part ${ }^{53}$ que Les Tablettes ${ }^{54}$ ont signalé mon poème Amour en termes élogieux et particulièrement l'image du début qui repose -vous vous en souvenez?- sur une coquille! La foi! Elle est très bonne...

Le Mouton Blanc est paru ${ }^{55}$. Vous devez l'avoir. Il pourra mieux faire, sans doute, mais le début n'est pas indifférent.

Dites-moi: dans quel sens entendez-vous que mon article sur Brauquier ${ }^{56}$ ait été le contraire de ce que vous eussiez écrit? en tant que chant local?

Je compte avoir en octobre une réponse pour l'édition de mon bouquin ${ }^{57}$. Après quoi j'envisagerais la publication d'une plaquette terminée depuis un mois, Le Passage d'Avril, une élégie rustique en 10 poésies ${ }^{58}$. - J'ai différents travaux en cours. Nous en reparlerons. Avez-vous conservé les deux ou trois poèmes que vous n'avez pas publiés $^{59}$ ? Pouvez-vous me les renvoyer?

\footnotetext{
A bientôt de vous lire et croyez-moi toujours très

cordialement vôtre

(sign.) Gabriel Audisio
}




198 Je n'ai pas encore reçu votre numéro d'octobre ${ }^{60}$. M'oubliez-vous ou bien, des retards imprévus...? Quoi de neuf?

199 J'ai un petit article (une ou deux pages de votre format) à tendances légèrement humoristiques sur L'Âge du nègre, ${ }^{61}$ essai de classification des influences de la race noire et de recherche des origines de son règne... Le voulez-vous pour Les idées et les faits d'un de vos prochains numéros?

Je compte bien recevoir de vos nouvelles un de ces jours proches.

(sign.) Gabriel Audisio

16

Alger

$28 / 10 / 1922$

lettre de GA à PAM (1 f., 160x168 mm.)

Alger. Le 28 octobre 1922

Cher Ami

Je vous envoie sous ce pli le petit «papier» dont il fut question ${ }^{62}$. Je pense que vous pourrez le lire malgré certains "collages» d'une élégance plus que douteuse. En tous cas, je vous en prie, faites-moi parvenir des épreuves; d'ici décembre vous aurez le temps.

J'attends votre numéro d'octobre ${ }^{63}$. - Je compte beaucoup sur celui du 15 novembre $^{64}$. La réédition de A.O.Barnabooth ${ }^{65}$ était nécessaire; je dois à ce livre d'excellentes heures.

210 A vous lire.

211 Toujours cordialement vôtre

212 (sign.) Gabriel Audisio

17

213 [Alger]

$214 \quad 13 / 11 / 1922$

215 lettre de GA à PAM (1 f., 214x272 mm.) 
Cher Ami,

218 Je vous avoue que je ne saisis pas très bien en quoi le "papier» ${ }^{66}$ que je vous avais adressé peut à la fois contenir des choses exactes, mais ne présenter d'intérêt que pour une revue de province. L'exactitude en soi est la même sous toutes les longitudes de la France et des colonies; je crois que seuls le déjà dit ou la médiocrité foncière s'opposent à la publication d'un texte. Ou bien ne faut-il pas faire offense à des dieux très établis, aussi bien en province qu'à Paris, je vous l'assure?

219 Quoi qu'il en soit il vous appartient de maintenir votre revue sur telle ligne que vous lui avez assignée et je ne saurais vous en vouloir.

Vous devez encore avoir dans vos cartons deux poèmes de moi ${ }^{67}$; j'aurai plaisir à augmenter ce nombre quand je possèderai des fragments qui puissent subir l'épreuve d'une publication isolée ${ }^{68}$.

Votre numéro d'octobre ne m'est pas encore parvenu ${ }^{69}$; son retard se serait-il prolongé à ce point? Dites-moi où vous en êtes et me croyez toujours très

cordialement vôtre

(sign.) Gabriel Audisio

18

224 Alger

carte postale de GA à PAM ( $1 \mathrm{f} ., 137$ x88 mm.) (Alger. Vue générale prise du Môle. - CAP. Edit. R. Dianoux. Alger 15) 
$$
\text { double } 313 \times 187 \mathrm{~mm} \text {., pliées et } 1 \mathrm{f} \text {. simple } 156 \times 195 \mathrm{~mm} \text {., le tout formant un cahier de } 10
$$
p. $)^{74}$

237 Alger. Le 17 mars 1923

238 Mon cher May,

239 Je vous envoie sous ce pli quelques considérations, qui, à condition de vous paraître valables, pourraient prendre place dans votre rubrique réservée à ce genre de travaux ${ }^{75}$. Il ne vous échappera pas que l'actualité de ces lignes ${ }^{76}$ voudrait que vous leur fissiez un sort dans votre plus prochain numéro. Il conviendrait que les épreuves, s'il y a lieu, fussent bien corrigées.

Répondez-moi, je vous prie, aussitôt que vous pourrez. Je vous en serai très obligé ainsi que de m'envoyer votre numéro d'Intentions du mois de janvier qui ne m'est point parvenu.

\section{0}




\section{2}

21

Je me fais écrire au G.G. ${ }^{79}$ à cause de certaines combinaisons horaires, voire topographiques, qui me permettent de mieux suivre le rythme des paquebots. Mais vous avez ici mon adresse, toute récente d'ailleurs, car depuis un mois je suis «l'homme qui a trouvé un appartement»!

Bien cordialement à vous

(sign.) Gabriel Audisio

10. Rue de Richelieu

Alger

$16 / 04 / 1923$

lettre de GA à PAM (1 f., 212x272 mm.)

contient: Odes et Prières par Jules Romains (5 ff., 154x197 mm., 158x188 mm., 158x218 mm., 149x195 mm., 158x210 mm. $)^{80}$

Alger. 16 Avril 1923

Cher Ami,

Dans une brève carte je vous demandais de me laisser le soin de parler du Traité de versification ${ }^{81}$ lorsqu'il serait paru. Je maintiens cette requête! ${ }^{82}$ Vous allez me prendre pour un spécialiste de «Romania»" «réflexions» qui m'ont été suggérées par la réédition des Odes et Prières de notre bon maitre $^{84}$. Les voulez-vous publier ${ }^{85}$ ? Vous y reconnaîtrez peut-être un point de vue spécial, non sans analogie d'ailleurs -dans le particulier- à ce que j'avais esquissé -en général- dans les Ecrits du Nord en un article ${ }^{86}$ qui semblait bien avoir donné de la satisfaction à Jules Romains.

Ne manquez pas de me renvoyer ce papier sans tarder si vous n'en avez pas l'utilisation en vue.

Votre numéro de janvier était brillant par ses collaborations ${ }^{87}$. Les traductions de Gabriel Miró ${ }^{88}$ m'ont vivement intéressé, aussi.

A bientôt à vous lire,

Très fidèlement vôtre

(sign.) Gabriel Audisio

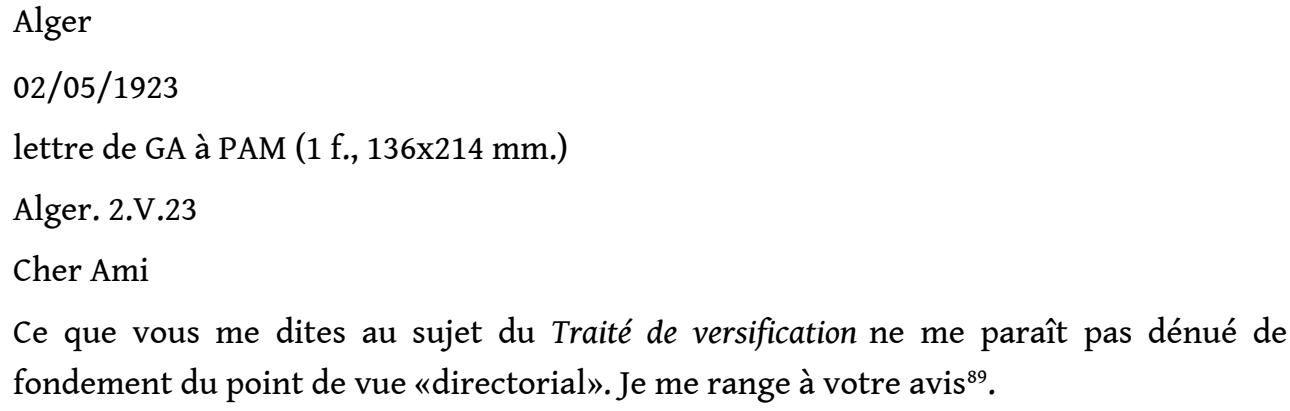

Ce que vous me dites au sujet du Traité de versification ne me parait pas dénué de fondement du point de vue «directorial». Je me range à votre avis ${ }^{89}$. 
Pour le reste je suis très mal préparé. Des éditions du Disque Vert je n'ai que «Notre-Mère la ville»" et «Réalités Fantastiques»"1. Ce dernier volume m'a vivement intéressé, mais je ne puis affirmer que j'aurais quelque chose de valable à en dire; ce qui n'engage pas $d u$ tout la valeur de l'ouvrage, j'y insiste. Je n'en pense peut-être pas autant de l'autre.

Quant aux «Tragiques» de Jouve, je les ignore. Si j'ai l'occasion, il se pourrait que j'en parlasse. Mais je ne vous promets rien à cet égard ${ }^{92}$.

Je pense vous annoncer bientôt la parution de mes pauvres Hommes au soleil, à l'ombre depuis si longtemps. On ne se presse guère aux éditions du candide ovin qui s'en charge! ${ }^{93}$

A vous, cordialement

(sign.) Gabriel Audisio jusqu'en octobre?

\section{3}

[Alger] (cachet de la Poste)

$13 / 08 / 1923$

carte postale de GA à PAM (1 f., 138x90 mm.) (Alger. - La synagogue et le Marché Randon. - CAP. Edit. R.Dianoux, Alger, 86)

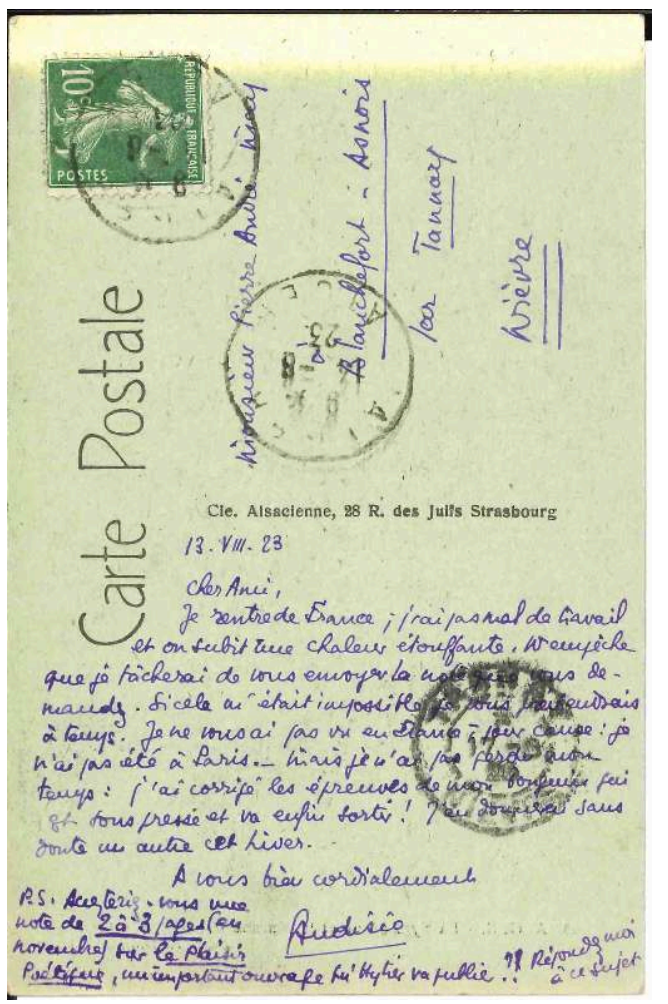

Cher Ami,

Je rentre de France; j'ai pas mal de travail et on subit une chaleur étouffante. N'empêche que je tâcherai de vous envoyer la note que vous demandez ${ }^{95}$. Si cela m'était 
impossible je vous préviendrais à temps. Je ne vous ai pas vu en France, -pour cause: je n'ai pas été à Paris.- Mais je n'ai pas perdu mon temps: j’ai corrigé les épreuves de mon bouquin qui est sous presse et va enfin sortir ${ }^{96}$ ! J'en donnerai sans doute un autre cet hiver ${ }^{97}$.

\section{A vous bien cordialement}

(sign.) Audisio

P.S. Accepteriez-vous une note de 2 à 3 pages (en novembre) sur Le plaisir Poétique, un important ouvrage qu'Hytier va publier' ${ }^{98}$ ? Répondez-moi à ce sujet.

\section{4}

[Alger] (cachet de la Poste)

29/08/[1923]

carte postale de GA à PAM (1 f., 137x90 mm.) (Alger. - Vue prise du Môle. Collection Idéale P.S. 50)

contient: Réalités Fantastiques, par Franz Hellens (Editions du Disque Vert - Bruxelles) (2 f., 140X196 mm. et 141x197 mm.) ${ }^{99}$

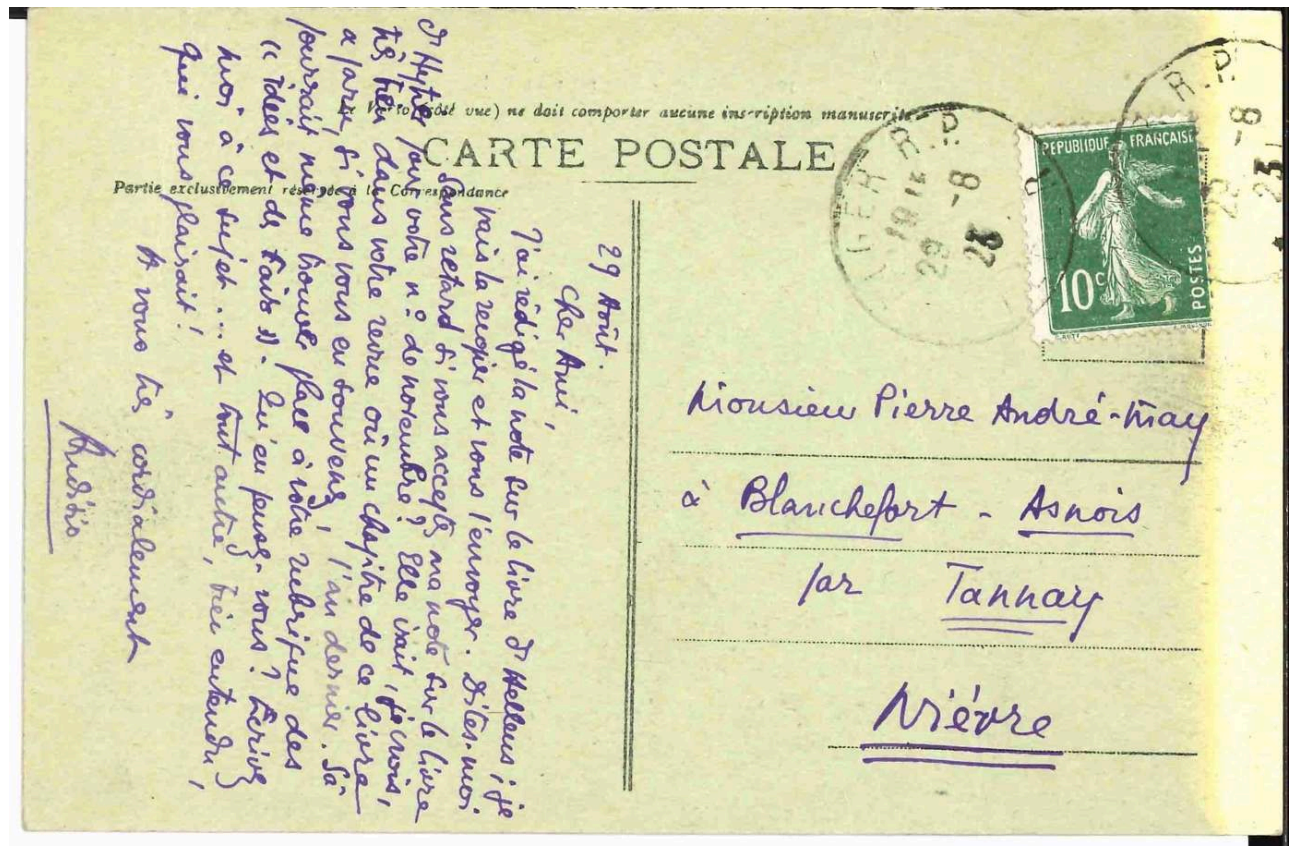

\section{Août,}

Cher Ami,

J'ai rédigé la note sur le livre d'Hellens; je vais la recopier et vous l'envoyer ${ }^{100}$. Dites-moi sans retard si vous acceptez ma note sur le livre d'Hytier pour votre n[umér]o de novembre? Elle irait, je crois, très bien dans votre revue où un chapitre de ce livre a paru, si vous vous en souvenez, l'an dernier ${ }^{101}$. Ça pourrait même trouver place à votre rubrique des «Idées et des Faits». Qu'en pensez-vous ? Ecrivez-moi à ce sujet... et tout autre, bien entendu, qui vous plairait!

$A$ vous très cordialement

(sign.) Audisio 




25

296 [Alger]

$297 \quad 04 / 10 / 1923$

298 lettre de GA à PAM ( 1 f. double 290x153 mm., pliée formant un pli de 4 pp.) 


\section{$4 \cdot 10 \cdot 23$}

Cher Ami",

Fallait le sire que vorus déanbiuliz dans ce pays fui n'est cher

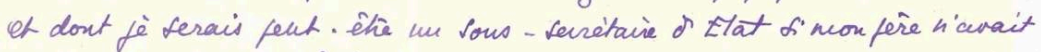
franchiles Alpes trop, tot! Vous a-t-on hien estance'? Jel'espere! wus aurz des firvenirs pitforesques, bien nodernes... Rapportz- vons des opinions ogfinitives sur le Eascisme on une insifestion de pâtes-aux-noncles de zestanrant de Pausiliffe?

Je ne fuis rien vous envygs lour octofre sur /'essai de hiasthe Esfuerré. T'eu ai lu les éfrenves cet été, daus la taniêre du candide ovin, c 'st trej cenarquable, - nais n'ayaut as le hire ea mains pi ne fuis en forles saram-

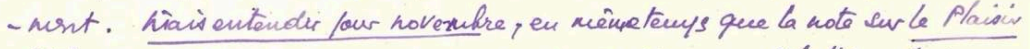
fótique qui sera farre, saus ancun doute. Fe laisfe del iótés" Les Fechuifues



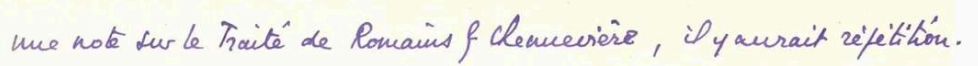
A cous lise.

Goygz a mes bons tentinents Colvietandisio

Fallait le dire que vous déambuliez dans ce pays ${ }^{102}$ qui m'est cher et dont je serais peutêtre un sous-secrétaire d'Etat si mon père n'avait franchi les Alpes trop tôt! Vous a-t-on bien estampé? Je l'espère! vous aurez des souvenirs pittoresques, bien modernes... 
Rapportez-vous des opinions définitives sur le Fascisme ou une indigestion de pâtesaux-moules du restaurant de Pausilippe ${ }^{103}$ ?

Je ne puis rien vous envoyer pour octobre sur l'essai de Marthe Esquerré104. J'en ai lu les épreuves cet été, dans la tanière du candide ovin; c'est très remarquable, -mais n'ayant pas le livre en mains je ne puis en parler savamment. Mais entendu pour novembre, en même temps que la note sur Le Plaisir Poétique qui sera paru, sans aucun doute ${ }^{105}$. Je laisse de côté «Les Techniques modernes du vers français» ${ }^{106}$; c'est un peu spécial; et puis, venant probablement après une note sur le Traité de Romains \& Chennevière ${ }^{107}$, il y aurait répétition.

A vous lire.

Croyez à mes bons sentiments

(sign.) Gabriel Audisio

\section{6}

\section{7}


Publieriez-vous volontiers, vous qui êtes accueillant aux espagnols ${ }^{115}$, un conte d'Alfonso Reyes, -critique et homme de lettres madrilène ${ }^{116}$, très répandu chez nous, au moins en amitié- qui me paraît fort divertissant par son humour, et très moderne par son sens de l'européen et du mouvement? Si oui (fixez-moi rapidement par une carte) j'en mettrai au point la traduction et vous l'enverrai.

Bien cordialement à vous

(sign.) Gabriel Audisio

\section{8}


Soyez sûr que je fais autour de vos Intentions tout le «bruit» que leur excellence mérite. Hélas! nous sommes, les uns et les autres, bien placés pour connaître que le "public» n'est pas aussi docile qu'on le souhaiterait. Faites-donc un dépôt -chez Rélin, 11, Rue d'Isly à Alger,- trois exemplaires, par exemple. Mais cette ville a si peu de «rendement» pour ce genre d'ouvrages, y compris mes œuvres solaires ${ }^{121}$ !

334 A vous très cordialement

(sign.) Gabriel Audisio

\section{9}

[Alger]

337 12/02/1924

338 carte postale de GA à PAM ( 1 f., 141x90 mm.) (Alger - La statue du Duc d'Orléans. Collection Idéale P.S.19)

Le 12.II.24

Cher Ami,

341 Avez-vous donné suite à votre projet de n[umér]o Espagnol? J'ai reçu des livres critiques de Marichalar ${ }^{122}$, Reyes ${ }^{123}$, Bergamín ${ }^{124}$, et la Revista de Occidente ${ }^{125} q u i$ contient des articles d'eux. Je pourrais vous faire une note sur cette activité qui met en jeu des familiers de chez nous, de Gide à Cocteau. Mlle Esquerré a réparé son oubli: lui en donnerez-vous la récompense? ${ }^{126}$ - J'irai vous voir dans la première quinzaine d'avril. Versez-vous des pleurs sur la mort du M[outon] B[lanc]? ${ }^{127}$ - Sic transit... ${ }^{128}$ c'est dommage! - Cordialement

(sign.) GAudisio

30

[Alger]

[10/03/1924] (date des deux cachets de la poste d'Alger)

carte postale de GA à PAM (1 f., 140x90 mm.) (Alger -Square de la Régence. Collection Idéale P.S. 20) 


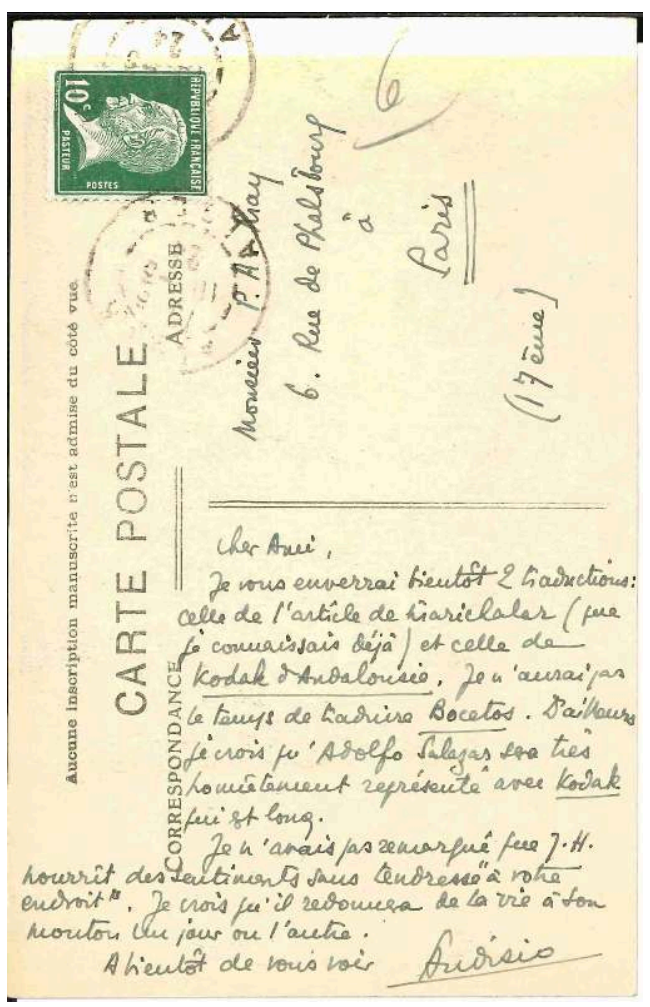

Cher Ami,

Je vous enverrai bientôt 2 traductions ${ }^{129}$ : celle de l'article de Marichalar (que je connaissais déjà) et celle de Kodak d'Andalousie. Je n'aurai pas le temps de traduire Bocetos. D'ailleurs je crois qu'Adolfo Salazar sera très honnêtement représenté avec Kodak qui est long.

Je n'avais pas remarqué que J.[ean]H.[ytier] nourrît des sentiments sans tendresse «à votre endroit». Je crois qu'il redonnera de la vie à son mouton un jour ou l'autre ${ }^{130}$.

A bientôt de vous voir

(sign.) GAudisio

31

Alger

$13 / 03 / 1924$

lettre de GA à PAM (1 f., 195x239 mm.)

contient: la traduction autographe par GA de Palus d'Antonio Marichalar (6 f., 158x217 $\mathrm{mm}.)^{131}$

Alger. Le 13 mars 1924

Cher Ami,

Je vous envoie sous ce pli la traduction de l'article de Marichalar, avec le texte imprimé ${ }^{132}$.

Je vous renvoie Bocetos que vraiment je n'ai pas le temps de traduire. Dans 3 ou 4 jours je vous enverrai la traduction de Kodak de Andalucía. ${ }^{133}$ 
359 A quand votre numéro? Si, comme il est possible, vous consacrez quelques considérations à l'exil de Miguel de Unamuno, vous joindrez, il va sans dire, mon nom à ceux des protestataires ${ }^{134}$.

Puis-je vous demander un service? Ces jours-ci sera achevé d'imprimer un petit livre de vers que «j'édite» moi-même, sans aucune firme. Je crains qu'il ne passe un peu inaperçu. Pourriez-vous, si cela est possible, insérer une annonce ${ }^{135}$ dans les pages de garde d'Intentions qui dirait :

Vient de Paraître. - Poème de la Joie, par Gabriel Audisio. Un volume tiré à 300 exemplaires sur vélin pur fil Lafuma, prix 7 francs. - En dépôt à la Maison des Amis des Livres $^{136}, 7$, Rue de l'Odéon, Paris-. ??

Si oui, je vous laisse le soin de disposer ces mots selon la place disponible. Vous m'obligeriez fort.

A vous très cordialement

(sign.) Gabriel Audisio

\section{2}

\section{3}


381

$A$ vous très cordialement

383

384

385

\section{Salazar ${ }^{144}$}

\section{4}

387 Alger

388 15/10/1924

389

390

391

392

393

395

Votre amicalement dévoué

396

\section{5}

397

398

399

400

Alger.15.10.24

Cher Ami, bouquin est fort remarquable. déjà été remarqué par d'autres.

(sign.) Gabriel Audisio

[Alger]

$04 / 11 / 1924$

4.11.24

lettre de GA à PAM (1 f., 136x212 mm.)

Je vous adresse une note sur le Corydon de Gide ${ }^{145}$. Dieu me garde d'être uranien! mais ce

Je vous laisse le soin d'apprécier si ce que je dis dans la «sous-note» de la page 3 n'a pas

4 J'aurai plaisir à recevoir de vos nouvelles quand vous aurez du loisir.

lettre de GA à PAM (1 f., 138x217 mm.) 
Chen Anci

J'eutio fort bier daus wor zaisons, nevis laistg. nesis

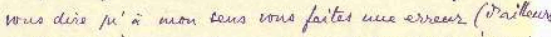

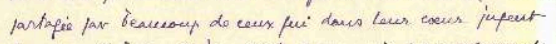

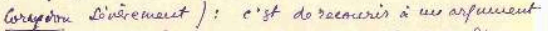

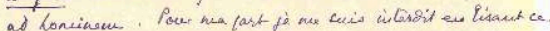



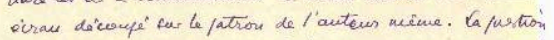

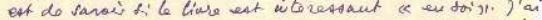

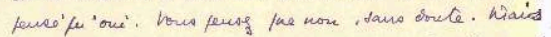
it ne fanctait fuand meime pas qui on en viert a' reprockes $\therefore$ Gride do a' aroir pas nus daces tón tivire ce fu'on

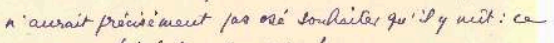
desait en vérite top freudien!

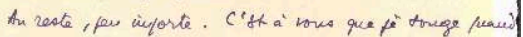
lav haverd un hiore ne fouses is eirise mue wote. Ze

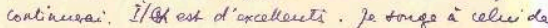



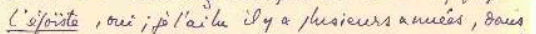

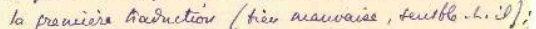
isu ai mine tarreit qualques ligues on Gimps que

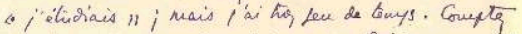

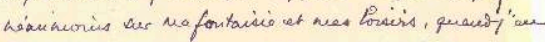
ai.

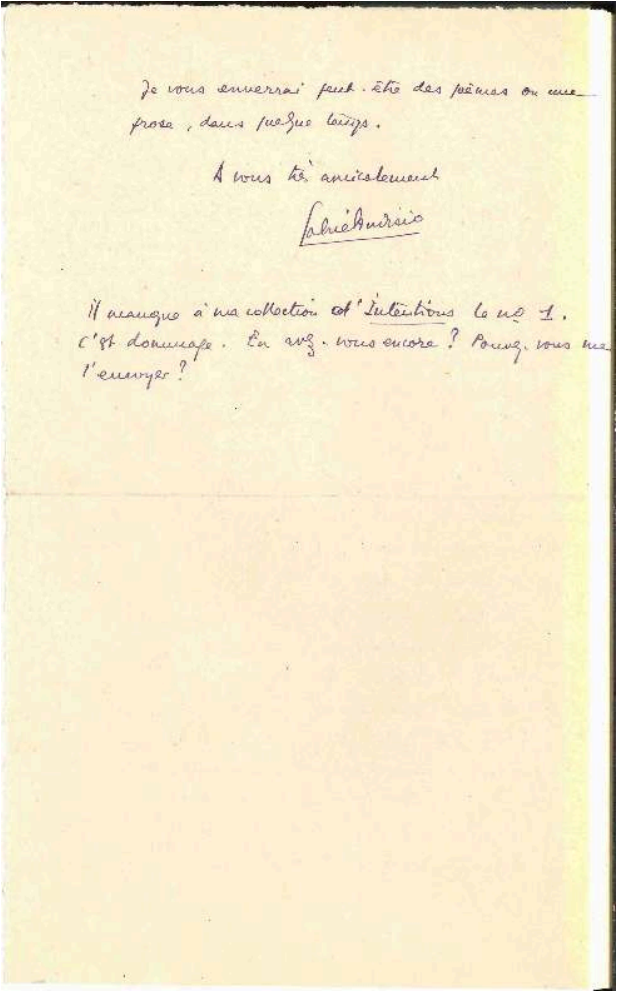

\section{Cher Ami}

J'entre fort bien dans vos raisons, mais laissez-moi vous dire qu'à mon sens vous faites une erreur (d'ailleurs partagée par beaucoup de ceux qui dans leur coeur jugent Corydon sévèrement): c'est de recourir à un argument ad hominem. Pour ma part je me suis interdit en lisant ce livre et en le commentant de mettre devant moi un écran découpé sur le patron de l'auteur même. La question est de savoir si le livre est 
intéressant «en soi». J'ai pensé que oui. Vous pensez que non, sans doute. Mais il ne faudrait quand même pas qu'on en vînt à reprocher à Gide de n'avoir pas mis dans son livre ce qu'on n'aurait précisément pas osé souhaiter qu'il y mît: ce serait en vérité trop freudien!

Au reste, peu importe. C'est à vous que je songe quand par hasard un livre me pousse à écrire une note. Je continuerai. Il en est d'excellents. Je songe à celui de Sichel dont vous avez autrefois donné un long fragment ${ }^{146}$. L'égoïste, ${ }^{147}$ oui, je l'ai lu il y a plusieurs années, dans la première traduction (bien mauvaise, semble-t-il); j'en ai même traduit quelques lignes du temps que «j'étudiais»; mais j'ai trop peu de temps. Comptez néanmoins sur ma fantaisie et mes loisirs, quand j'en ai.

Il manque à ma collection d'Intentions le n[umér]o 1. C'est dommage. En avez-vous encore? Pouvez-vous me l'envoyer?

\section{6}

[Alger]

$14 / 11 / 1924$

lettre de GA à PAM (1 f., 135x218 mm.) jours, par Pierre Sichel (1 f., 180x217 mm.) ${ }^{148}$ passage de Wilde ${ }^{150} . . . v$ voire...

\section{7}

418 Alger

419 24/11/1924

Cher Ami,

Je vous envoie ci-joint quelques pages de prose. Si elles vous intéressent j'aimerai les voir publiées dans Intentions, sinon renvoyez-les moi ${ }^{151}$.

Bien amicalement à vous

(sign.) Gabriel Audisio 
38

426 [Alger]

$427[11 / 01 / 1925]^{152}$

428 carte postale de GA à PAM (1 f., 142X90) (Alger - Les Facultés. Collection Idéale Photo Albert 8)

429 Cher Ami,

430 Je ne reçois rien de vous ni Intentions. Je pense que cela n'est dû à rien de fâcheux. Les quelques papiers que je vous ai envoyés, il y a un ou deux mois ${ }^{153}$, vous sont-ils parvenus?

431 Ecrivez-moi quelques lignes. A vous très cordialement

432 (sign.) Gabriel Audisio

39

433 [Alger]

$434 \quad 12 / 01 / 1925$

435

lettre de GA à APM (1 f., 200x214 mm.)

436

contient: carte postale (lettre 38)

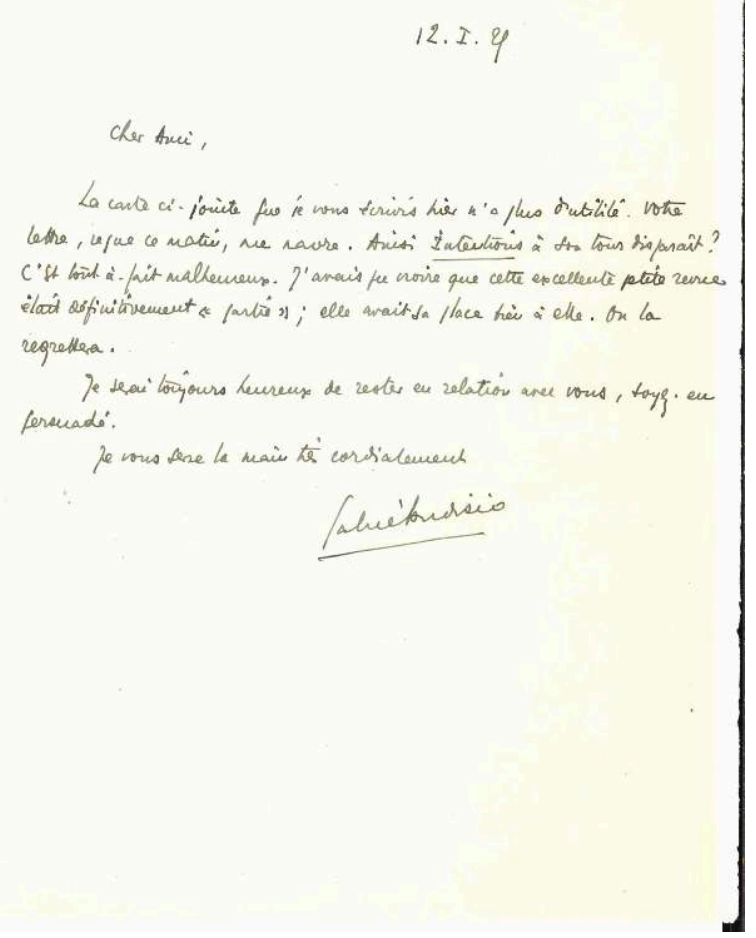

Cher Ami,

La carte ci-jointe ${ }^{154}$ que je vous écrivis hier n'a plus d'utilité. Votre lettre, reçue ce matin, me navre. Ainsi Intentions à son tour disparait ${ }^{155}$ ? C'est tout à fait malheureux. 
J'avais pu croire que cette excellente petite revue était définitivement «partie»; elle avait sa place bien à elle. On la regrettera.

Je serai toujours heureux de rester en relation avec vous, soyez-en persuadé.

441 Je vous serre la main très cordialement

(sign.) Gabriel Audisio

DOCUMENTS AUTOGRAPHES DE GABRIEL AUDISIO

PUBLIÉS DANS INTENTIONS

1. Amour, poème daté du 02/06/1921 et publié avec variantes (Intentions 4, p.23). Voici la version originale :



\section{Amour}

De ce bleu sans défaillances,

Uni comme le bonheur,-

De ce bleu où les sillages

Persistent plus que des joies,-

De cet azur, étendu

Sous l'ivresse des étés,

Où mainte rive vient boire

A pleins bords les purs soleils,-

Amour! Amour gonflé de ces lumières,

Amour si bleu, si vibrant de ce bleu

Qui est en moi, qui est en nous, 
Comme le signe de la race,

Comme la trame de la vie,

Et qui nous est tout souvenir,

Et qui nous prit jusqu'à pleurer,

Sur une plage, un matin d'août !

GAudisio

2 juin 1921

2. Vision extra-rétinienne et Psychologie littéraire, article daté du 16/03/1923

(Intentions 13, pp.23-25)

3. compte rendu de Jules Romains, Odes et Prières, Paris, NRF (Intentions 14-15, pp.

57-59)

4. compte rendu de Franz Hellens, Réalités fantastiques, Bruxelles, Disque vert (Intentions 18, pp.30-31)

5. compte rendu de Jean Hytier, Le plaisir poétique. Etude de psychologie, Paris, Le Mouton Blanc (Intentions 19, pp.26-28)

6. traduction d'Antonio Marichalar, Palus (Intentions 23-24, pp.35-38)

7. traduction d'Adolfo Salazar, Note autobiographique (Intentions 23-24, p.43)

8. traduction d'Adolfo Salazar, Kodak d'Andalousie (Intentions 23-24, pp.43-54)

9. compte rendu de Jean-Richard Bloch, Sur un Cargo, Paris, NRF, daté à Alger le 09/07/1924 (Intentions 26, pp.39-40)

DOCUMENTS AUTOGRAPHES DE GABRIEL AUDISIO

NON PUBLIÉS DANS INTENTIONS 


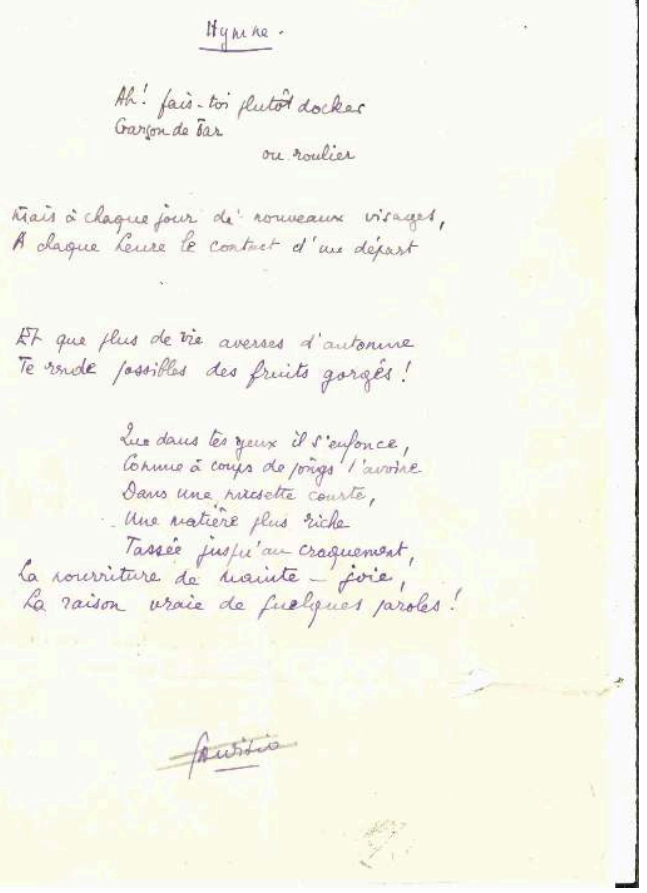

1. Hymne, poème non daté (1921?)

Hymne

Ah! fais-toi plutôt docker

Garçon de bar

ou roulier

Mais à chaque jour de nouveaux visages,

A chaque heure le contact d'un départ

Et que plus de vie averses d'automne

Te rende possibles des fruits gorgés!

Que dans tes yeux il s'enfonce,

Comme à coups de poings l'avoine

Dans une musette courte,

Une matière plus riche

Tassée jusqu'au craquement,

La nourriture de mainte joie,

La raison vraie de quelques paroles!

GAudisio

2-3. Deux poèmes datés 1922: 1. Contraste 2. Escale 


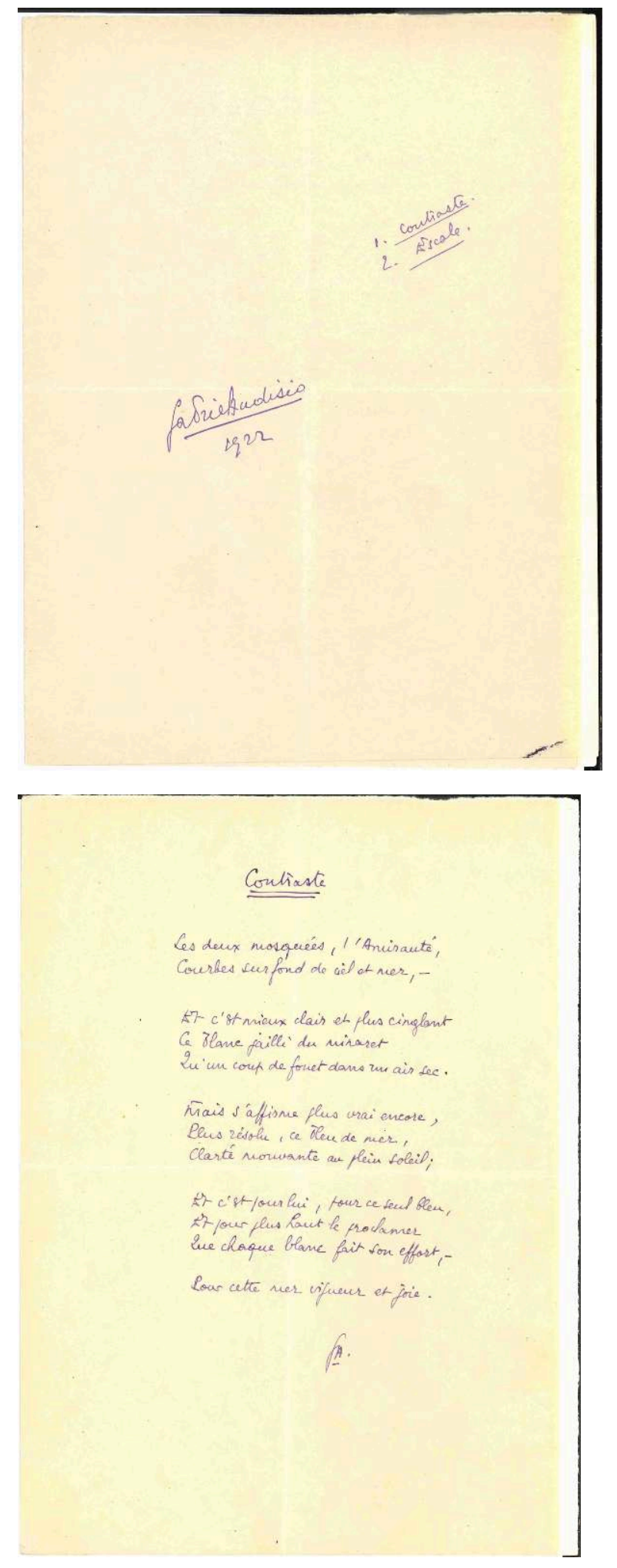

\section{Contraste}

Les deux mosquées, l'Amirauté,

Courbes sur fond de ciel et mer, -

Et c'est mieux clair et plus cinglant 
Ce blanc jailli du minaret

Qu'un coup de fouet dans un air sec.

Mais s'affirme plus vrai encore,

Plus résolu, ce bleu de mer,

Clarté mouvante au plein soleil;

Et c'est pour lui, pour ce seul bleu,

Et pour plus haut le proclamer

Que chaque blanc fait son effort, -

Pour cette mer vigueur et joie.

GA.

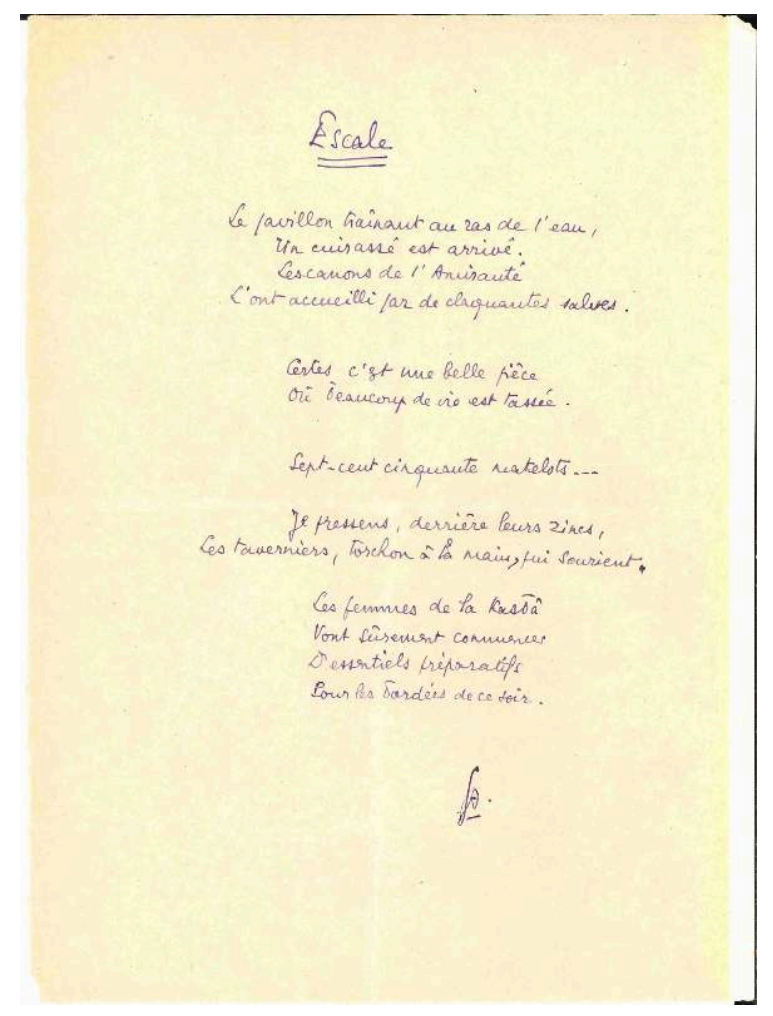

Escale

Le pavillon traînant au ras de l'eau,

Un cuirassé est arrivé.

Les canons de l'Amirauté

L'ont accueilli par de claquantes salves.

Certes c'est une belle pièce

Où beaucoup de vie est tassée.

Sept-cent cinquante matelots...

Je pressens, derrière leurs zincs,

Les taverniers, torchon à la main, qui sourient. 
Les femmes de la kasbâ

Vont sûrement commencer

D’essentiels préparatifs

Pour les bordées de ce soir.

GA.

4. compte rendu de: Plainte contre inconnu, par Pierre Drieu la Rochelle; Une création du monde de nos jours, par Pierre Sichel

Une question s'avance, la lanterne en main, pareille à M. de Soubise: il s'agit de trouver «la personnalité». Ténèbres, mystère, dissociation, tâtonnements, inquiétude, que savons-nous? Le moi est polymorphe, la personnalité est insaisissable... Je crains bien qu'on n'ait facilité la chose, en multipliant à l'envi les difficultés! Et l'obscurité qui règne sur tout cela est un peu comme celle d'un théâtre. Côté cour: Freud ; côté jardin: Pirandello.

Ni Drieu la Rochelle, ni Pierre Sichel n'échappent tout-à-fait à ce jeu. Mais ils y sont tellement engagés que nous sommes bel et bien pris. Chacun pourtant vient d'un air si différent qu'il n'est pas sans intérêt de les confronter.

Drieu la Rochelle ne veut pas que nous ignorions rien de lui, ni même de son entourage. Connais-toi toi-même, devient connaissez-moi et partant m'aidez à me connaître. Il cherche, il cherche passionnément, il court de l'un à l'autre, il menace, il gémit, il exalte. Il arrache des touffes de vérité, mais le bouquet n'est jamais fait. - Sichel tourne autour de l'objet, patiemment; il l'éclaire peu à peu; il «construit» avec de la lumière. Il ne lâche pas la proie pour l'ombre.

Le premier vit dans un monde tout concret; on s'intéresse à ses créatures comme à des créatures données qu'on connaît bien. Elles existent en dehors de nous, mais on pourrait s'identifier à elles. - L'autre est au centre d'une sphère tout idéale; il nous met l'argile en main pour créer ses êtres. Nous ne risquons pas de nous confondre avec eux, mais ils tirent sur leur débat notre sollicitude.

L'opposition de ces pôles, concret et abstrait, explique le renversement des styles: c'est celui qui construit dont la phrase sinue, s'étire, enveloppe, comme sous-marine ou éthérée; l'autre, qui peine sur le vrai sol, a des mots durs et cassants qui sont autant de coups de truelle et de maillet.

Du moins ces deux pôles ont-ils leur équateur: le pathétique.

\section{Gabriel Audisio}

\section{ANNEXES}

\section{APPENDICES}




\section{NOTES}

1. Béatrice Mousli, Intentions. Histoire d'une revue littéraire des années vingt, Paris, Ent'revues, 1995.

Le livre est une version adaptée de la thèse de doctorat de l'auteur, présentée en 1993 à l'Université de Paris IV, Sorbonne: Intentions, revue littéraire 1922-1924.

2. La correspondance entre Valery Larbaud et Pierre André-May comporte soixante pièces. Pour Henri Hoppenot, Adrienne Monnier, André Gide, Max Jacob, Louis Aragon, Paul Claudel, Jean Cocteau, Paul Valéry et Jules Supervielle, la relation épistolaire est plus modeste et presque exclusivement unidirectionnelle (dirigée à André-May).

3. L'existence de la documentation inédite et son importance pour la connaissance de la diffusion de l'œuvre de F. García Lorca hors des frontières espagnoles, a été signalée pour la première fois en 1998: Christian de Paepe, «Lorca y 'La jeune littérature espagnole': nueva luz sobre el número especial de la revista Intentions (Paris, 1924)», in A. Soria Olmedo, M. J. Sánchez Montes, \& J. Varo Zafra (eds.), Federico García Lorca, clásico moderno (1898-1998), Granada, Diputación de Granada, 2000, p. 205-219. La version autographe retrouvée du cycle Petenera (du recueil Poema del cante jondo) et la traduction française manuscrite de Jean Cassou ont été reproduites dans le catalogue accompagnant l'exposition Federico García Lorca 1898-1936, tenue à Anvers, à la galerie d'art Van de Velde, entre septembre et novembre 1999. Voir: Christian de Paepe \& Bart Vonck, «Federico García Lorca 1898-1936», Anvers, Ronny Van de Velde, 1999, p. 194-206. Depuis lors quelques études ont été consacrées au numéro extraordinaire d'Intentions (23-24, avril-mai 1924), entièrement dédié à La jeune littérature espagnole : Domingo Ródenas de Moya, «La joven literatura española ante 'la petite chapelle' francesa: Larbaud, Marichalar e Intentions», en: Hispanogalia, I, 2004-2005, p. 107-133, et Christian De Paepe, "Aquella intentona de Intentions. De "La jeune littérature espagnole” (Intentions, 1924) a Poesía española. Antología 1915-1931 (G. Diego, 1932) », in E. Dehennin \& Chr. De Paepe, Principios modernos y creatividad expresiva en la poesía española contemporánea. Poemas y ensayos, Amsterdam-New York, 2009, p. 239-264.

4. Textes autographes d'Antonio Marichalar, José Bergamín, Rogelio Buendía, Juan Chabás y Martí, Gerardo Diego, Antonio Espina, Federico García Lorca, Alonso Quesada, Adolfo Salazar, Fernando Vela, Guillermo de Torre, etc.

5. Documents autographes de Mathilde Pomès, Georges Pillement, Gabriel Audisio, Jean Cassou, Valery Larbaud, etc. La documentation épistolaire de Marcelle Auclair a déjà été publiée : Christian De Paepe, « La correspondance de Marcelle Auclair avec Pierre André-May, directeur de la revue Intentions ", en M. Ramond, E. Ramos-Izquierdo \& J. Roger (eds.), Hommage à Milagros Ezquerro. Théorie et fiction, México/Paris, Rilma 2/Adelh, 2009, p. 143-158.

6. Les papiers littéraires de Gabriel Audisio ont été déposés à la Bibliothèque Municipale de Marseille. Des recherches entreprises pour tâcher de retrouver la correspondance de P. AndréMay à G. Audisio n'ont donné aucun résultat. Je tiens à remercier tout spécialement le docteur Michel Audisio, fils de l'écrivain, le professeur Gabriel Audisio, son homonyme, monsieur François Larbre, directeur de la Bibliothèque Municipale de Marseille et madame Michèle Coulet, conservateur des Fonds rares et précieux, pour leurs conseils, aide et renseignements.

7. Dans sa lettre du 4 octobre 1923, Audisio s'exclame en apprenant que P. André-May vient de faire un voyage en Italie: «Fallait-le dire que vous déambuliez dans ce pays qui m'est cher et dont je serais peut-être un sous-secrétaire d'Etat si mon père n'avait franchi les Alpes trop tôt. [...] Rapportez-vous des opinions définitives sur le Fascisme ou une indigestion de pâtes-aux-moules du restaurant de Pausilippe?» (lettre 25).

8. Plusieurs papiers retrouvés portent l'en-tête du Journal de médecine interne.

9. Pour les revues littéraires de cette époque : Jean-Michel Place \& André Vasseur, Bibliographie des Revues et Journaux littéraires des XIX et XX ${ }^{e}$ siècles, tome troisième 1915-1930, Paris, Editions Jean-Michel Place, 1977.

10. Je souligne. 
11. Poème publié dans Intentions ( $\left.\mathrm{n}^{\circ} 4, \mathrm{p} .23\right)$ avec une 'variante': villages pour sillages (v.3). A propos de cette coquille, voir les commentaires du poète dans les lettres 7 et 14 .

12. Poème non publié dans Intentions mais conservé dans la documentation. Voir les lettres 2 et 14. Le texte du poème dans Appendice 2.1.

13. Il s'agit du livre en préparation Hommes au soleil qui ne sera finalement publié qu'en septembre 1923 à Mâcon (voir la lettre 23 du 13/08/1923).

14. L'Afrique latine: pour le service des lettres et des arts français en Afrique du Nord, revue mensuelle publiée à Alger entre 1921 et 1924. Le chiffre 41 (ou 11) est douteux.

15. La Criée, revue mensuelle marseillaise des années vingt.

16. Ces deux poèmes, non publiés dans Intentions mais conservés dans la documentation, sont reproduits dans Appendice 2.2-3 (voir aussi la lettre 14).

17. Jean Hytier, né à Paris (1899), décédé à New-York (1983), ami d'Audisio, fondateur de la revue unanimiste Le Mouton Blanc (1922), auteur de recueils de poésies (Le violon chante et pleure, 1916, La belle sorcière, 1924, Cinquième saison, 1933), directeur au Ministère de l'Education nationale après la guerre, professeur de littérature française à plusieurs universités (Columbia University, Californie (Davis), Massachusetts, Alger), spécialiste de Valéry, Gide, Pascal. Il publia dans Intentions 6 (1922): Les images sensorielles dans le plaisir poétique. Audisio consacre une note de lecture à Le plaisir poétique. Etude de psychologie (Paris, Le Mouton blanc, 1923) dans Intentions 19 (1923). Voir aussi les lettres 23 et 24 et les notes correspondantes.

18. Louis Brauquier (1900-1976), journaliste, critique littéraire, poète (premier recueil Et l'au-delà de Suez, mentionné par Audisio dans la lettre 11), peintre et photographe; a voyagé de par le monde comme agent de la Marine Marchande, tout en continuant à écrire. L'oeuvre poétique complète dans: Je connais des îles lointaines (Paris, Editions de la Table Ronde, 1994). Malgré la recommandation d' Audisio, aucun texte de Brauquier n'a été publié dans Intentions. Tout porte à croire qu'André-May ait même critiqué un article d'Audisio sur lui (voir la lettre 14). Il meurt en septembre 1976 d'une congestion cérébrale en se rendant à Paris pour visiter son ami Audisio malade qui, en 1966, avait publié, dans la collection Poètes d'aujourd'hui, Paris, Seghers, le volume sur Louis Brauquier. La correspondance entre les deux amis a été publiée par Roger Duchêne: Louis BRAUQUIER, Lettres à Gabriel Audisio. 1920-1960, Marseille, Marcel Scheifer, 1982.

19. GA corrige "demandez" en "demander".

20. Francis Ponge (Montpellier 1899-1988). La recommandation de Gabriel Audisio a été vaine: aucun texte de Ponge n'a paru dans Intentions.

21. Il s'agit probablement de la revue Accords, fondée à Paris par André Desson et André Harlaire. Le premier numéro ne paraîtrait finalement qu'en mai 1924. Voir la lettre 32.

22. Les quatre exemplaires justificatifs correspondent au $n^{\circ} 4$ d'avril 1922, dans lequel fut publié le poème Amour (p.23), première collaboration d' Audisio à la revue. Pour les numéros 1 à 20 un tirage de luxe de 20 exemplaires sur papier de Hollande, numérotés de 1 à 20 , complétait le tirage ordinaire de 500 exemplaires. A partir du n² 21 jusqu'au dernier (28-29-30), le tirage de luxe a été réduit à 10 exemplaires numérotés 1 à 10 . Pour le $n^{\circ} 9$, spécialement consacré à Valery Larbaud, il avait été tiré 50 exemplaires numérotés I à L sur papier Lafuma et 20 exemplaires sur papier de Hollande, numérotés de 1 à 20 et signés par Valery Larbaud.

23. Contrairement à ce que pensait G.Audisio, la coquille villages pour la version originale manuscrite sillages dans la première strophe de son poème Amour:

De ce bleu sans défaillances,

Uni comme le bonheur,-

De ce bleu où les sillages

Persistent plus que des joies,-...

ne semble pas avoir importuné les lecteurs, bien au contraire. En septembre GA écrit à PAM: «... Hytier me fait part que Les Tablettes ont signalé mon poème Amour en termes élogieux et 
particulièrement l'image du début qui repose -vous vous en souvenez?- sur une coquille! La foi! Elle est très bonne...» (voir la lettre 14).

24. Lors de sa visite à Paris, Audisio a dû suggérer à André-May une forme de participation ou collaboration à la direction de la revue, soit de lui-même, soit de Jean Hytier, soit de tous les deux. De toute façon, le 24 mai 1922, Audisio revient sur la question pour annoncer à André-May que l'idée d'une collaboration ne peut plus être maintenue puisque Hytier allait fonder sa propre revue: «...Jean Hytier [...] réalise son projet de revue. Voilà qui m'empêchera sans doute de vous reparler du projet de participation auquel j'avais songé et que je vous avais suggéré au cours de ma dernière visite à Paris.» (voir la lettre 11).

25. La famille André-May était propriétaire du Château de Blanchefort à Asnois (près de Tannay) dans la Nièvre.

26. Il s'agit de l'article Imagination créatrice et activité physique, publié effectivement dans le $\mathrm{n}^{\circ} 5$ (mai 1922) d'Intentions, dans la rubrique Les Idées et les faits (pp.24-27). Vu l'absence du manuscrit parmi les documents conservés, il est impossible de déterminer si le titre actuel correspond ou non au titre original donné par l'auteur.

27. Les deux dernières pages (31-32) du $n^{\circ} 4$ (avril 1922) offraient deux Poèmes plastiques: La Belle Gueuse et Les Gerbiers du poète de l'Aveyron Roger Frène (1878-1939).

28. Gabriel Audisio avait publié son poème Amour dans le $n^{\circ} 4$ (voir la lettre 7).

29. Marcel Proust, un des 'maîtres' d'Intentions, avait publié dans le $n^{\circ} 4$ (pp.1-20) sa première collaboration à la revue: Etrange et douloureuse raison d'un projet de mariage, extrait de Sodome et Gomorrhe.

30. [Dominique] O[ctave] Mannoni (1899-1989), philosophe, psychologue et ethnographe, connu pour son essai Psychologie de la colonisation (Paris, Seuil, 1950), avait publié dans le $n^{\circ} 4$ (pp.24-30) une longue étude élogieuse sur L'unanimisme, mouvement dont il était un grand adepte et défenseur. Audisio l'avait rencontré au Centre d'Etudes Supérieures de Strasbourg où, après la première guerre mondiale, il avait suivi des cours de droit et de civilisation musulmane.

31. Franz (Audisio écrit Frantz) Hellens (1881-1972) (pseudonyme de Frédéric van Ermengem), romancier, poète et critique belge, fonda en mai 1921 (avec André Salmon) la revue Signaux de France et de Belgique qui deviendra plus tard, après son interruption début 1922, Le Disque vert (mai 1922-1925). Le $\mathrm{n}^{\circ} 6$ d'Intentions (juin 1922) annonce la parution du Disque vert. Les $\mathrm{n}^{\circ} 10$ et 11 (déc. 1922 - janv.1923) par contre annoncent les Ecrits du Nord du même Hellens. En novembre 1922, ce dernier titre avait en effet pris la relève de sa 'Revue mensuelle de Littérature' avec un premier numéro de la 2ème série. Le $n^{\circ} 18$ (septembre 1923) d'Intentions dit que Le Disque vert réapparaîtra en octobre, ce qui fut effectivement le cas. A partir de son $\mathrm{n}^{\circ} 19$ (nov.1923), Intentions annonce régulièrement le volume spécial du Disque Vert dédié à Max Jacob.

32. Voir note 29 (lettre 8).

33. Gabriel Audisio était à la recherche d'un éditeur pour son recueil de poésie Hommes au soleil. Beaucoup dépendait en effet de l'appui financier grâce à quelque prix littéraire. Finalement le recueil reçut le Prix Primice Mendès pour l'année 1922. Audisio reparlera encore plusieurs fois du lent cheminement de son livre (lettres 12, 13, 14, 22 et 23) qui sera finalement publié (automne 1923) par les éditions du Mouton Blanc (Maupré, Imprimerie Protat Frères, Mâcon) dirigées par son ami Jean Hytier.

34. Les Ecrits Nouveaux, revue mensuelle (Paris, Emile-Paul Frères), fondée par André Germain, parue entre fin 1917 et juin 1922, continuée à partir de mars 1923 par La Revue Européenne. Elle est très présente dans Intentions, aussi bien dans la rubrique Les Revues $\left(\mathrm{n}^{\circ} 1\right.$ à $\left.7,10,13\right)$ comme dans les pages d'annonces $\left(n^{\circ} 3,5,6\right)$.

35. Maurice Martin du Gard (1896-1970), cousin de Roger, écrivain et journaliste, fondateur des Nouvelles Littéraires (1922). Intentions publie presque dans chaque numéro une annonce de cette revue et reproduit dans le $n^{\circ} 3$ (mars 1922) un poème Assez de chants glacés de M. Martin du Gard. 
36. Pierre Drieu la Rochelle (Paris, 1893-1945), romancier et essayiste, ne figure qu'indirectement dans Intentions grâce à la revue des revues. Audisio rédigea un bref compte rendu de sa nouvelle Plainte contre inconnu (Paris, Gallimard, 1924) qui n'a jamais été publié mais dont le manuscrit se trouve dans la documentation conservée (voir Appendice, 2.4).

37. Allusion probable à des maisons d'éditions et des publications jugées de mauvais aloi par Pierre André-May. Pour La Criée voir la lettre 1.

38. Jean Hytier fonda son 'organe du classicisme moderne', Le Mouton Blanc, en 1922. Il en sera au début le rédacteur en chef, avec comme directeur Pierre Favre. La revue ne paraîtra que sept fois (septembre 1922-novembre 1924). Le dernier numéro était entièrement pris en charge par Hytier. Audisio collabora fréquemment à la revue de son ami en publiant des poèmes $\left(n^{\circ} 1\right)$ et des études critiques ( $n^{\circ} 3,2^{e}$ série $n^{\circ} 1$, dernier numéro). Voir aussi la lettre 7 et la note 14

39. Dans le $n^{\circ} 5$ (mai 1922), Audisio venait de publier, dans la rubrique Les Idées et les faits, son bref essai Imagination créatrice et activité physique (pp.24-27). Voir aussi la lettre 8.

40. Louis Brauquier (voir lettre 2, note 18) accomplit dans les années 1922-1923 son service militaire dans l'Allemagne occupée après la 1ère guerre mondiale.

41. L.Brauquier publia son premier recueil de poésie Et l'au-delà de Suez en 1922 à Aix-en-Provence aux éditions de la Société de la revue Le Feu. Audisio en fit une brève critique dans Le Disque Vert de septembre 1922 ( $n^{\circ}$ 5, 1ère année, p.[140]).

42. C'est à dire la veille, le mardi 20 juin, le samedi suivant étant le 24 juin 1922.

43. Il s'agit de L'invention artistique et le milieu extérieur, publié dans la rubrique Les Idées et les faits du n 7 (juillet-août 1922, pp.29-32) d'Intentions. La version manuscrite n'est pas conservée.

44. Gabriel Audisio publia dans le $n^{\circ} 2$ de la 1ère année (juin 1922, pp. [31-32]) du Disque vert trois poèmes: Poissonnerie I -II (datés Tigzirt, octobre 1921) et L'Hélice (sans date). La coquille 'province' pour 'Provence' se lit dans le v.3 du poème I: Matin d'août, en province, les pêcheurs.... Une erreur d'orthographe dans les vv. 1 et 13 du même poème: Odeurs, relans de la poissonnerie....

45. Audisio écrit: Frantz Hellens.

46. Voir lettre 11, note 33.

47. Voir note 43.

48. Ceci n'est vrai que pour la première année d'Intentions. Sur les trois années de vie, la revue a publié en tout une soixantaine de notes 'relatives à tel ou tel livre' mais cinq seulement correspondent aux $\mathrm{n}^{\circ} 1$ à 10 .

49. Cet article de Gabriel Audisio sur Lucienne ne se trouve pas entre les documents retrouvés et n'a pas été publié non plus dans Intentions. André-May consacre lui-même, dans le $\mathrm{n}^{\circ} 8$ de septembre-octobre de 1922 (pp.24-25), une note de lecture au roman de J. Romains.

50. Pour le livre Hommes au soleil, voir lettre 11, note 33.

51. Le $n^{\circ} 9$ de novembre 1922 était tout spécialement consacré à Valery (GA écrit Valéry) Larbaud. 52. On peut supposer qu'il s'agit du bref essai L'invention artistique et le milieu extérieur, publié dans le $\mathrm{n}^{\circ} 7$ d'Intentions (juillet-août 1922).

53. Audisio remplace "signale" par "fait part".

54. Les Tablettes (littéraires et artistiques), revue de Saint-Raphaël, dirigée par Ph. De Magneux. Pour la coquille «villages» pour «sillages», voir la lettre 7 et la note 23 correspondante.

55. Le premier numéro du Mouton Blanc venait de paraître en septembre 1922. Audisio y figure avec cinq poèmes extraits de son livre Hommes au soleil (pp.3-7), en compagnie, entre autres, de Jules Romains, Henri Petiot et Jean Hytier. Sous la rubrique des Revues, on annonce aussi Intentions.

56. Gabriel Audisio se réfère probablement à son bref article sur le recueil Et l'au-delà de Suez de Louis Brauquier, paru dans Le Disque Vert de septembre 1922 ( $1^{\text {ère }}$ année, n 5, p.[140]).

57. Nouvelle référence à son livre Hommes au soleil (voir les lettres 12, 13, 22 et 23 et les notes correspondantes). 
58. Passage d'Avril, daté du 7 septembre 1922, se trouve, sous forme de manuscrit, dans la boîte 57, dossier «poèmes» du Fonds Gabriel Audisio, à la Bibliothèque Municipale de Marseille. Il ne semble pas avoir été édité. Le passage d'avril et Traversée de mai s'annoncent comme 'deux poèmes amicaux inédits' parmi les données bibliographiques ('du même auteur') du roman de Gabriel Audisio Trois hommes et un minaret (Paris, F .Rieder et $C^{\text {ie }}$, 1926). La version de Traversée de mai, portant la note 'fait en Alger de mai à décembre 1924', conservée également à Marseille, semble être une impression du manuscrit mais sans mention d'éditeur (renseignements fournis par Mme M. Coulet).

59. Les trois poèmes envoyés non publiés sont: Hymne, Contraste et Escale (voir les lettres 1, 2, 17).

60. Le seul $n^{\circ} 8$ de la revue couvrait les mois de septembre et octobre.

61. Texte jamais publié dans Intentions ni conservé parmi les documents.

62. Il s'agit sans doute $d u$ «petit article» L'Âge du Nègre promis dans la lettre antérieure 15 et discuté dans la lettre suivante 17 .

63. Voir la note 60 à la lettre 15.

64. Le $\mathrm{n}^{\circ} 9$ d'Intentions était entièrement consacré à Valery Larbaud (voir la lettre 14).

65. La première édition de ce livre de Valery Larbaud, dont le titre complet était A.O.Barnabooth, ses œuvres complètes, c'est-à-dire un conte, ses poésies et son journal intime (Paris, Editions de la Nouvelle Revue Française), date de 1913. Chez le même éditeur parut en 1922 A.O.Barnabooth, son journal intime, 1ère édition séparée du journal.

66. Sans doute le texte $L$ Âge du Nègre annoncé dans la lettre 15 et envoyé avec la lettre 16.

67. En fait André-May gardait encore 3 poèmes. Voir les lettres 1,2 et 14 et les notes correspondantes.

68. Après Amour ( $\mathrm{n}^{\circ}$ 4, avril 1922), aucun poème d'Audisio n'a été publié ultérieurement dans Intentions.

69. Gabriel Audisio répète la demande de ses lettres antérieures 15 et 16 . Le $n^{\circ} 8$ était daté 'septembre-octobre'.

70. Le volume 9 (novembre 1922) est un numéro spécial entièrement consacré à Valery Larbaud.

71. Audisio écrit 'celle'.

72. A part le feuillet avec un portrait de Larbaud par Paul-Emile Bécat (1920), le numéro spécial compte une vingtaine de collaborations, avec entre autres des textes de Ch. Du Bos, L.-P. Fargue, J. Giraudoux, R. Gómez de la Serna, E. Jaloux, A. Monnier, P. Morand, J. Romains, Saint-John Perse, J. Supervielle... Des textes de Larbaud lui-même et une bibliographie complètent le volume. 73. Le $n^{\circ} 8$ (sept.-oct. 1922) offrait des poèmes de Henri Hoppenot, de Cl.-André Puget et de J.J.Van Dooren. André-May aurait-il retardé pendant si longtemps l'envoi de ce numéro, tant de fois réclamé par Audisio, parce qu'il y publiait sa propre note de lecture sur Lucienne de Jules Romains, au lieu de la note envoyée par Audisio avec sa lettre 13 (voir note 49)?

74. Le document porte de nombreuses indications techniques au crayon de la main de Pierre André-May, destinées toutes à l'imprimeur (référence à la rubrique des Notes, les différents corps de lettre du titre, du texte, des notes, etc.). André-May biffe la date originale: '16 mars 1923' et antidate le texte ' 1 er mars 1923'.

75. Le bref essai Vision extra-rétinienne et psychologie littéraire a été publié dans le $\mathrm{n}^{\circ} 13$ de mars 1923 sous la rubrique Les Idées et les faits (pp.23-25).

76. Jules Romains (1885-1972), auteur (sous son vrai nom de Louis Farigoule) d'une thèse La vision extra-rétinienne et le sens paroptique. Recherches de psycho-physiologie expérimentale et de physiologie histologique (Paris, Gallimard, Editions de La Nouvelle Revue Française, 1920), venait d'écrire La vision extra-rétinienne, état de la question au 15 janvier 1923, dans La Nouvelle Revue Française de février $1923\left(\mathrm{n}^{\circ} 113\right)$.

77. Date hypothétique probable qui tient compte aussi bien du jour de la semaine indiqué dans la lettre ("lundi") que du contenu du message qui traite de l'article envoyé avec la lettre précédente (samedi 17 mars). Le lundi 19 mars paraît difficilement envisageable pour des raisons évidentes 
de courrier et le lundi 2 avril serait en flagrante contradiction avec "la promptitude" de la décision prise par André-May.

78. Voir la lettre 19 et les notes 75 et 76.

79. Le Gouvernement Général à Alger, adresse qui figure sur la carte postale du 16 octobre 1922 (cfr. lettre 15).

80. Ce document, écrit sur des feuillets de dimensions et de qualité différentes, porte de nombreuses indications au crayon de la main de Pierre André-May (mention de la rubrique Notes. La poésie, le nom de l'éditeur du volume, les corps de lettre du texte, du titre, des notes et des citations).

81. Le Petit Traité de versification, oeuvre conjointe de Georges Chennevière et de Jules Romains, sera publié à Paris (Gallimard) en mai 1923 aux Editions de la Nouvelle Revue Française.

82. Phrase écrite en marge du texte et signalée par une flèche.

83. Célèbre revue consacrée à l'étude des langues et littératures romanes, fondée en 1872 par Paul Meyer et Gaston Paris.

84. La première édition des Odes et Prières de Jules Romains date de 1913. La réédition, commentée par Audisio, est de 1923 (Paris, Editions de la Nouvelle Revue Française).

85. Le compte rendu fut publié dans le $n^{\circ}$ 14-15 d'avril-mai 1923 dans la rubrique des Notes (pp. 57-59).

86. Gabriel Audisio, L'oeuvre bâtie de Jules Romains, dans Ecrits du Nord, 1ère année, 2ème série, $n^{\circ} 1$ (novembre 1922), pp.180-183.

87. Audisio dut recevoir enfin le numéro manquant de janvier 1923 qui contient, entre autres, des textes signés Léon-Paul Fargue, François Mauriac, Edmond Jaloux, Jacques Benoîst-Méchin et Darius Milhaud.

88. Référence aux $n^{\circ} 12$ et 13 d'Intentions (février et mars 1923) qui reproduisaient des textes de Gabriel Miró dans une traduction de Valery Larbaud (respectivement pp.1-11 et pp.13-22).

89. Dans sa réponse à la lettre antérieure, Pierre André-May a probablement décliné l'offre d'Audisio de faire un compte rendu du Petit traité de versification de Chennevière et de Jules Romains

90. Recueil de poésie d'Odilon-Jean Périer, Notre Mère la Ville. Poèmes 1921-1922, Editions du Disque Vert, Paris-Bruxelles, 1922.

91. Franz Hellens, Réalités fantastiques, Editions du Disque vert, Paris-Bruxelles, 1923.

92. Pierre Jean Jouve, Tragiques, suivis du Voyage sentimental, Paris, Delamain, Boutelleau et Cie, 1922. Aucun texte d'Audisio sur Jouve dans Intentions.

93. Par un double jeu de mots Gabriel Audisio se réfère d'abord au titre de son recueil et ensuite aux éditions du Mouton Blanc où le livre paraîtra finalement (voir lettre 11 et la note 38).

94. Le $\mathrm{n}^{\circ}$ triple 4-5-6 du Disque vert (1ère année, 2ème série) correspondait aux mois de févriermars-avril 1923. Le premier $n^{\circ}$ de la $2^{\text {ème }}$ année fut effectivement publié en octobre 1923.

95. Il s'agit sans doute de la note sur le livre de Franz Hellens, Réalités fantastiques, qu'Audisio enverra plus tard (voir la lettre 24 ainsi que la lettre 22 et les notes correspondantes).

96. Pour le recueil Hommes au soleil, voir les lettres 11, 12, 13, 14 et 22.

97. Allusion probable à son recueil Poème de la joie (Paris, Editions du Solitaire, 1924).

98. Jean Hytier présenta sa thèse sur 'le plaisir poétique' en 1922 à la Faculté des Lettres de l'Université de Lyon. Un fragment, Les images sensorielles dans le plaisir poétique, avait été publié dans la revue Intentions (num.6, juin 1922, pp.24-32). L'ouvrage sera publié à la fin de l'année 1923 par les Editions du Mouton Blanc. GA envoie son compte rendu du livre avec une lettre datée du 22 novembre 1923 (voir la lettre 27).

99. Le document porte des indications techniques au crayon d'André-May, destinées à l'imprimeur (référence à la rubrique Le Roman, corps de lettre...).

100. La note sur Réalités Fantastiques n'accompagnait donc pas la carte postale et elle fut sans doute envoyée peu de temps après. Pour des raisons pratiques, je l'ai rangée avec le document 24. 
La note même fut publiée dans le $\mathrm{n}^{\circ} 18$ d'Intentions (septembre-octobre 1923, rubrique Notes. La poésie, pp.30-31).

101. Pour le livre de Jean Hytier, voir la lettre précédente et la note 98 . Voir aussi la note 17 à la lettre 2.

102. L'Italie, pays d'origine de la famille Audisio.

103. Colline et faubourg qui abrite les quartiers élégants de Naples. C'est là que se trouverait le tombeau de Virgile. Jadis le lieu était obligatoire pour toute visite culturelle d'Italie. On peut supposer que Pierre André-May aura envoyé une carte postale à Audisio depuis Naples. Le souvenir littéraire du fameux vers de El Desdichado de G.de Nerval: «Rends-moi le Pausilippe et la mer d'Italie...» peut aussi avoir joué.

104. nn

105. Pour ce livre de Jean Hytier, voir aussi les lettres 23, 24, 27 et 28.

106. Jean Hytier, Les techniques modernes du vers français, Paris, Les Presses Universitaires de France, 1923.

107. Référence au Petit Traité de versification de Jules Romains et Georges Chennevière (voir les lettres 21 et 22 et la note 89). Il n'y a pas eu de note sur cet ouvrage dans Intentions.

108. Gabriel Audisio, Réalités fantastiques, par Franz Hellens, note publiée dans le $n^{\circ} 18$ (septembre-octobre 1923), dans la rubrique Notes. Le Roman, pp.30-31.

109. Référence faisant suite à ce qu'Audisio annonçait dans la lettre précédente.

110. Voir les lettres 23, 24 et 25.

111. Le texte autographe présente des indications au crayon de Pierre André-May destinées à l'imprimeur.

112. Dans sa note Deux poètes méditerranéens ( $\mathrm{n}^{\circ} 18-19$, septembre-octobre 1923, pp.29-30), AndréMay commente favorablement le recueil Hommes au soleil de Gabriel Audisio.

113. Comme expliqué (note 104), le manuscrit original de ce texte, jamais publié dans Intentions, n'a pas été retrouvé.

114. La note sur le livre Le Plaisir poétique de Jean Hytier a été conservée. Elle fut publiée en novembre 1923.

115. A part la participation de Gómez de la Serna au numéro d'hommage à Valery Larbaud $\left(n^{\circ} 9\right)$, Intentions avait déjà publié des textes du romancier espagnol Gabriel Miró ( $n^{\circ} 12$ et 13) et de l'argentin Ricardo Güiraldes. André-May était alors en pleine préparation du numéro spécial consacré à la jeune littérature espagnole (n²3-24, avril-mai 1924).

116. L'écrivain et diplomate Alfonso Reyes (1889-1959), poète, romancier et critique, n'était pas espagnol mais mexicain (voir lettre 28). Entre 1914 et 1924, il résida à Madrid, travaillant au Centre d'Etudes Historiques et publiant des chroniques régulières dans la presse locale, ce qui explique l'erreur d'Audisio. Le conte qu'il se proposait de traduire provenait peut-être du livre $E l$ plano oblicuo, publié à Madrid, Tipografía Europa, en 1920.

117. Voir les notes précédentes 104 et 113.

118. La note de lecture sur Le Plaisir poétique de Hytier fut publiée dans le $\mathrm{n}^{\circ} 19$ d'Intentions (novembre 1923, pp.26-28). Voir les notes 98, 106 et 1145.

119. Dans sa réponse à la lettre 27, André-May aura sans doute fait remarquer à Audisio qu'Alfonso Reyes n'était pas espagnol.

120. Première référence à la collaboration de Gabriel Audisio au numéro spécial La jeune littérature espagnole ( $\mathrm{n}^{\circ}$ 23-24 d'Intentions, avril-mai 1924).

121. Allusion au titre de son recueil poétique Hommes au soleil. Voir la note 33 à la lettre 11.

122. Antonio Marichalar (1893-1973), critique littéraire et d'art, biographe, collaborateur de plusieurs revues, entre autres de la Revista de Occidente, auteur d'essais sur Valéry, Claudel, Bergson, James Joyce, Faulkner, etc. Il fut le principal organisateur du numéro spécial d'Intentions dédié à la jeune littérature espagnole.

123. Alfonso Reyes (voir note 116). 
124. José Bergamín (1895-1983), critique littéraire espagnol, en 1923 auteur de El cohete y la estrella, plus tard fondateur de la revue Cruz y Raya, collaborateur du numéro spécial sur la jeune littérature espagnole.

125. La Revista de Occidente a été fondée en 1923 par le philosophe espagnol José Ortega y Gasset. Elle prit une part active dans le renouveau de la culture et de l'art européens de l'entre-deuxguerres.

126. Voir les lettres 24 et 27. Malgré l'envoi de l'essai de Marthe Esquerré, la note de lecture n'a jamais été publiée dans Intentions.

127. Le $n^{\circ} 2$ de la 2ème série du Mouton Blanc (portant la date de novembre 1923) ne vit le jour qu'au début de 1924. Tout le monde était convaincu que la revue éphémère était condamnée. Mais après un an de silence, le tout «dernier numéro», complètement rédigé par Jean Hytier, allait paraître en novembre 1924. Voir la prophétie de Gabriel Audisio à ce sujet dans la lettre 30.

128. Première partie de la locution latine 'sic transit gloria mundi': c'est ainsi que disparaît toute gloire terrestre.

129. Les deux traductions que Gabriel Audisio a faites pour le numéro spécial de la jeune littérature espagnole sont: d'Antonio Marichalar, Palus (pp.35-38) et Kodak d'Andalousie d'Adolfo Salazar (pp.43-54). Bocetos, le deuxième texte de Salazar envoyé par André-May pour être traduit, ne sera ni traduit ni publié (voir aussi les lettres 31 et 33).

130. Voir la note 127.

131. Le texte présente des indications techniques manuscrites d'André-May.

132. La traduction autographe de Palus de Marichalar par Audisio a été conservée mais pas le texte espagnol original.

133. Le texte original de Bocetos ne se retrouve pas parmi les documents conservés. Par contre, la traduction autographe par Audisio de l'original espagnol Kodak de Andalucía d'Adolfo Salazar (16 ff., 158x217 mm.) et de la note biobibliographique ( $1 \mathrm{f}$., 157x196 mm.) est bel et bien conservée. Ces derniers documents portent la trace de très nombreuses indications et interventions manuscrites d'André-May destinées à l'imprimeur.

134. La revue Intentions publie dans son $n^{\circ} 22$ (mars 1924) une note de protestation signée Pierre de Lanux: Sur la déportation de D. Miguel de Unamuno par le général Primo de Rivera, dictateur d'Espagne (p.33). Il n'y a pas de liste de protestataires proprement dite.

135. Le texte intégral de l'annonce du livre Poème de la joie se trouve à la p.43 du $\mathrm{n}^{\circ} 22 \mathrm{~d}^{\prime}$ Intentions (mars 1924).

136. La Maison des Amis des Livres, à la fois bibliothèque, librairie, société de lecture, maison d'édition et lieu de rencontre de l'avant-garde littéraire de l'entre-deux-guerres, fut fondée en novembre 1915 par Adrienne Monnier (1892-1955).

137. Il s'agit du n²3-24 (avril-mai 1924), complètement dédié à la jeune littérature espagnole et pour lequel Audisio avait fait plusieurs traductions.

138. La revue Accords, Cahiers mensuels de littérature, dirigée par André Harlaire et André Desson, venait de publier son premier numéro (mai 1924). On y recense le recueil Hommes au soleil (p.24). Le $n^{\circ} 2$ (juin 1924) parle de la revue Intentions qui, elle, cite Accords dans le $n^{\circ} 25$ (juin 1924, p.62 et p.64). Le dernier numéro (3-4) d'Accords parut en novembre de 1924. Voir la lettre 6 et la note 21. 139. Le texte porte des indications et des corrections manuscrites d'André-May à l'intention de l'imprimeur.

140. Le livre Sur un cargo. A la découverte du monde connu, récits de voyage de l'essayiste, romancier, homme de revue et militant politique Jean-Richard Bloch (1884-947), fut publié à Paris en 1924. La note d'Audisio parut effectivement dans le $n^{\circ} 26$ d'Intentions (juillet-août 1924) sous la rubrique Littérature générale (pp.39-40). J.-R. Bloch fut directeur de la collection Prosateurs français contemporains des Editions F.Rieder et $C^{\text {ie }}$ à Paris, collection qui allait publier en 1926 le roman de Gabriel Audisio, Trois hommes et un minaret, dédié «A Jean-Richard Bloch en affectueuse amitié». 
141. Trois hommes et un minaret daté «Alger, 1924» dans l'édition de 1926 (voir note antérieure).

142. La famille de P.André-May avait l'habitude de passer les vacances à Asnois dans la Nièvre. Voir note 25.

143. Au-delà des Pyrénées (en espagnol dans le texte).

144. Gabriel Audisio avait traduit pour le numéro spécial de la jeune littérature espagnole (Intentions, 23-24) des textes d'Antonio Marichalar et d'Adolfo Salazar (voir lettre 30). Marichalar a donc remercié Audisio mais pas Salazar.

145. Après deux éditions partielles (1911 et 1920), à tirage limité, la première édition commerciale de Corydon d'André Gide (1869-1951) eut lieu en mai 1924, à Paris, par les Editions de la Nouvelle Revue Française. La note d'Audisio n'a pas été retrouvée et Intentions ne parlera pas du livre. Pour la réaction négative de Pierre André-May, voir la lettre 35.

146. Le texte de Pierre Sichel publié dans Intentions ( $\mathrm{n}^{\circ} 8$, septembre-octobre 1922, pp.6-19) s'intitulait Conception d'un autre. Voir aussi la lettre 36.

147. L'égoïste, livre de George Meredith (1879), fut publié dans une nouvelle traduction par Yvonne Canque chez Gallimard à Paris en 1924. J'ignore à quelle traduction française antérieure Audisio fait allusion.

148. La note d'Audisio, présentant des indications techniques autographes d'André-May, destinées à l'imprimeur, n'a jamais été publiée dans Intentions. Pour le texte, voir Appendice 2.4.

149. Jeu de mots sur le prénom Pierre de Drieu la Rochelle et de Sichel.

150. Oscar Wilde (1854-1900) séjourna à Alger entre le 17 janvier et le 3 février 1895.

151. Parmi la documentation conservée il n'y a pas de trace de ces 'pages de prose'. Aucun texte d'Audisio n'a été publié dans Intentions après le n 26 de juillet-août 1924.

152. Carte postale sans date ni lieu, avec l'adresse de Pierre André-May à Paris, mais ne présentant ni timbre-poste ni cachet de la poste. Elle a été envoyée avec la lettre $39 \mathrm{du} 12$ janvier 1925 , ce qui permet de lui assigner la date de la veille («La carte ci-jointe que je vous écrivis hier...»).

153. Voir la lettre $37 \mathrm{du} 24$ novembre 1924.

154. Voir la carte postale 38 .

155. Le dernier volume d'Intentions, réunissant les n²8-29-30, était daté de décembre 1924. Plusieurs autres 'petites' revues avaient disparu la même année, L'œuf dur, Le mouton blanc, Interventions, Accords...

\section{RÉSUMÉS}

A partir de documents autographes inédits, l'étude analyse la relation culturelle et littéraire et les liens d'amitié entre Pierre André-May (1901-1999), fondateur, directeur et éditeur de la revue Intentions (1922-1924), et le jeune poète et critique Gabriel Audisio (1900-1978). La présence accusée de cet intellectuel français parmi un lot de papiers littéraires axés avant tout sur le monde hispanique, s'explique par sa participation active, comme traducteur, au numéro spécial de la revue sur La jeune littérature espagnole ( $\mathrm{n}^{\circ}$ 23-24, avril-mai 1924). L'analyse de la correspondance permet de se faire une idée des premières années de production littéraire de l'écrivain, résidant à l'époque en Algérie. La correspondance compte 39 pièces et couvre exactement les trois années d'existence d'Intentions. Malgré l'absence de la deuxième voix de ce dialogue littéraire et artistique, le point de vue critique d'un jeune intellectuel français vivant 
dans la périphérie (l'Afrique française), jette une lumière originale et complémentaire sur l'histoire d'une revue littéraire avant tout parisienne.

A partir de documentos autógrafos inéditos, el presente estudio analiza las relaciones culturales y literarias y la amistad entre Pierre André-May (1901-1999), fundador, director y editor de la revista Intentions (1922-1924), y el poeta y crítico literario Gabriel Audisio (1900-1978). La presencia muy marcada de este intelectual dentro de un conjunto de papeles literarios relacionados sobre todo con el mundo hispánico, se explica por su colaboración activa, como traductor, al número especial de la revista, dedicado a La joven literatura española ( $\mathrm{n}^{\circ} 23-24$, abrilmayo de 1924). El conocimiento de la correspondencia permite hacerse una idea de la importancia de los primeros años de producción literaria del escritor francés, residente en Argel. La correspondencia consta de un total de 39 piezas que cubren los tres años de vida de la revista. A pesar de la ausencia de la segunda voz de este diálogo literario-artístico, el punto de vista de un joven intelectual francés establecido en la periferia, echa una luz original sobre la historia de una revista de vanguardia antes que nada parisina.

Exclusively based on unpublished manuscripts, the present study analyses the cultural, intellectual and human relationship between Pierre André-May (1901-1999), director and editor of the French review Intentions (1922-1924), and the poet and literary critic Gabriel Audisio (1900-1978). The high presence of this French intellectual in a collection of literary papers dealing mainly with the Spanish world, can be explained by his active collaboration as a translator to the special volume of the review, dedicated to La jeune littérature espagnole ( ${ }^{\circ} 23-24$, april-may 1924). The correspondence between the two men enables to get an idea of the first literary production of the young writer, living in Alger at that time. The whole of the correspondence (39 letters, postcards and visiting cards) and other documents covers the three years lifetime of the review. In spite of the absence of the second voice of this literary-artistic dialogue, the sharp opinions of a young French artist, settled in the intellectual periphery, shed a new and original light on the history of a literary review which reflects above all the cultural trends in the French capital.

\section{INDEX}

Mots-clés : Gabriel Audisio, Pierre André-May, poésie, transferts culturels, France-España Palabras claves : Gabriel Audisio, Pierre André-May, poesía, intercambios culturales, FranciaEspaña

Keywords : Gabriel Audisio, Pierre André-May, poetry, transculturalism, cultural transfers, France-Espagne

\section{AUTEUR \\ CHRISTIAN DE PAEPE}

Université de Louvain 